\title{
Hydrophobic Modification of Copper Nanospheres for Incorpora- tion into Poloxamer Micelles, Aggregated Micellar Nanocages and Supramolecular Assemblies
}

\author{
Yunlong $\mathrm{Xu}^{1,2}$, Kaspars Melkis ${ }^{2}$, Chinn Tyng $\mathrm{Sia}^{2}$ and Dipak K. Sarker ${ }^{2, *, \dagger}$ \\ ${ }^{1}$ School of Electrical Engineering, Jiujiang Vocational and Technical College, Jiangxi Province, 332007, \\ People's Republic of China; ${ }^{2}$ Interfacial Nanotechnology Group, School of Pharmacy and Biomolecular Sci- \\ ences, The University of Brighton, Moulsecoomb Science Campus, Lewes Road, Brighton, BN2 4GJ, UK
}

\begin{abstract}
Background: Polymer nanogels are increasingly used for the encapsulation of nano-solids and quantum dots such as in advanced forms of drug and therapeutic isotope delivery.

Objective: Unlike ex vivo application of systems in vivo application and internalization are likely to suffer from aspects of failure to ensure safety and biocompatibility. Biocompatible hydrophilic poloxamer (Pluronic F108 and F68) micelles were studied by light scattering and tensiometry.

Method: The micelles of nano-gels are synthetic heteropolymer aggregates, which are used to encapsulate drugs but in this study chemically-modified (hydrophobized) copper nano-spheres, for the purposes of demonstration for further application and medical use. Copper benzoate nano-particles (CuBzNPs) were produced by maceration and subsequently stabilized in Pluronic F108 solution was added at different concentrations.

Results: The resulting particle size increase was studied by dynamic light scattering. Moderate size increase was observed at low Pluronic F108 concentrations, which indicated successful coating, but at higher F108 concentrations large size agglomerates formed. Coated copper benzoate nano-particles (CuBzNPs) were fabricated as a proof-of-principle and as a substitute for bare metal nano-particles (MNs), which were not successfully entrained in the poloxamer nano-gel. As part of the synthesis copper benzoate $(\mathrm{CuBz})$ beads and their characterization through contact angle measurements were performed.

Conclusion: Micelles sizes of $4 \mathrm{~nm}$ for F68 Pluronic at equilibrium surface tensions of 36 $\mathrm{mNm}^{-1}$ were captured in weak, 1.25 to 2.0 Pas pseudoplastic gels fabricated from hydroxypropylmethylcellulose (HPMC).
\end{abstract}

Received: January 23, 2018

Revised: June 15,2018

Accepted: June 21, 2018

DOI:

$10.2174 / 2405461503666180628155014$

Keywords: Encapsulation, hydrophobic, nano-gel, nano-solids, micelle, therapy.

\section{INTRODUCTION}

Colloidal dispersions are used ubiquitously in applications as diverse as pharmacy and electronic engineering [1, 2]. Copper nanoparticles (NPs)

\footnotetext{
*Address correspondence to this author at the Interfacial Nanotechnology Group, School of Pharmacy and Biomolecular Sciences, The University of Brighton, Moulsecoomb Science Campus, Lewes Road, Brighton, BN2 4GJ, UK; Tel: +44 (0) 1273 641779; Fax: +44 (0) 1273 642674;

E-mail: d.k.sarker@brighton.ac.uk

${ }^{\dagger}$ Primary author
}

have a particular significance since copper possess paramagnetic capability and radio-isotopes of copper have a desirable half-life [3-5]. Copper itself is toxic and although it is required by the body in a micro-nutrient capacity, the lethal dose for copper is in the low milligram range for an adult. However, by encapsulating the copper this helps to alleviate its pronounced and typical transition metal oxidative cell damaging potential [6-9] and the cellular and organism injury that ensues $[10,11]$. Nanospheres of exceptionally small nano-scale dimensions of 1-3 nm are referred to as quantum 
dots and may also be used in semiconductor roles. They are increasingly used in a photonic role and in the generation of surface plasmons for imaging and energy transfer processes, again often related to imaging and microscopy. Medical use of NPs is now commonplace and these are frequently utilized for medical treatment via photo-dynamic therapy (PDT), which converts high energy light into infra-red light $[1,12-14]$. Soft matter nanoassemblies include liposomes and vesicles, which are up to $200-1000 \mathrm{~nm}$ or more in size, can be as small as $5-10 \mathrm{~nm}$ for surfactant micelles but are more customarily $50-80 \mathrm{~nm}$ for nanoemulsions and polymer micelles [15-18]. Metal NPs due to their small size and increased surface area exhibit very different physicochemical properties, which make them very useful as therapeutic and diagnostic agents and as vehicles of drug delivery [19]. Some NPs of $1-5 \mathrm{~nm}$ in size are also quantum dots (QDs) with unique optical properties. QDs show improved fluorescence, a narrow emission band and resistance to fading, when compared to traditional organic molecules, which can be utilized in several ways but are especially useful in 3Dimaging and as triggers for light-driven chemical changes in vivo [7,9]. Metal NPs can be made from gold, iron, silver, copper, iron oxides, manganese oxide, cobalt, gadolinium [20] and other elements [21], with a summary list provided in Table 1.

Metal NPs have several disadvantages, predominantly in that they are usually water insoluble, they tend to agglomerate, can be toxic or cause immunogenic reactions and are quickly eliminated by the reticuloendothelial system (RES), which is the basis of foreign body removal from the blood and tissues [25]. Metal cellular toxicity is thought to be due to the generation of metallic ions that inhibit the enzyme thioredoxin reductase, leading to sub-cellular mitochondrial damage and reactive oxygen species proliferation. Sabella et al. [26] propose the "Trojan horse" mechanism of metal NP toxicity, where NPs that are internalized by energy dependent processes, such as endocytosis, i.e., the process that normally protects cells from toxic agents by of internalization of the agent. Gamucci et al. [25] have given brief description of nanoparticle biocompatibility related to different types of coatings of products and the materials employed. Larger bare particles of $>500 \mathrm{~nm}$ are primarily internalized via cellular processes such as, micropinocytosis or phagocyto- sis mechanisms. Alternatively, particles in the range $20-200 \mathrm{~nm}$, and often with useful catalytic, optical and magnetic properties [5], are efficiently taken up by macrophages or antigen-presenting cells via clathrin-coated endocytosis. Disguising of the NP surface by a coating can be achieved by chemical conjugation or physisorption coating of poly (ethyleneglycol) (PEG), which neutralizes the metal surface and makes it hydrophilic, prolonging NP circulation time. Many of these issues can be overcome by appropriately dispersing metal and metal oxide NPs into synthetic and naturally occurring polymers or self-assemblies [3, 24]. Liposomes are a common encapsulation vehicle $[12,19]$ and several examples of already licensed anti-cancer drugs or chemical agents encapsulated by liposomes include the Visudyne ${ }^{\circledR}$, Ambisome ${ }^{\circledR}$ and Doxil ${ }^{\circledR}$ vesicular therapeutic formulations. Among those Visudyne ${ }^{\circledR}$ used for treatment of macular degeneration of the eye by photodynamic therapy (PDT) and emission of light contains the optically-active organic molecule, verteporfin.

In this article, work involves encapsulation of metal NPs for chemotherapy (CTX), radiotherapy (RTX) and phototherapy (PDT) applications. Use of copper (II) oxide (CuO), one of the more stable forms of copper is now widespread in pharmacy and medicine $[3,23,27]$. The compound has a use for quantum dots, as a coloring agent or for electroluminescence from diodes, which means its extension as, for example a diagnostic tool. Cupric oxide functioning as a $p$-type (electron accepting) semiconductor for use in light emitting diode (LED) lamps is possible when layered with an $n$ type junction semiconductor. The compound also can be used for ultraviolet (UV), visible and infrared (IR) photoluminescence applications and for lasers [23]. This type of photo-physics research may prove to be routinely used for skin applications and soft tissue oncology via the ongoing medical goal of designing more effective and targeted ways excising inaccessible tumors [19]. An insightful means for treating inoperable cancers is to use light-activated, tumor-destroying species often based on propagation of IR or UV light [3, 12]. This photodynamic therapy (PDT) approach allows clinicians to activate the labelled drug (active species) only in the tumor itself and are thus ideally suited to brain, spinal cord, eye and heart photo-surgery but may also be used to destroy infections $[1,12,22,28,29]$. At present, lasers represent one of the more common means of 
Table 1. Examples of currently used metals nanoparticles (NPs), Benefits of encapsulation and summary of typical current medical products and researched objects.

\begin{tabular}{|c|c|c|c|c|}
\hline Details & Example of Use & Size (nm) & Key Properties & Medical Applications \\
\hline Cobalt (0) & Imaging aid & $2-7.5$ & SPM particles & $\begin{array}{l}\text { CA for XCT, SPECT, US, } \\
\text { NCT; magnetic separation; } \\
\text { cell labelling; DDN; MH } \\
\text { treatment of tumors, MRI }\end{array}$ \\
\hline $\begin{array}{l}\text { Copper (I) oxide, } \\
\qquad \mathrm{Cu}_{2} \mathrm{O}\end{array}$ & $\begin{array}{l}\text { Conjugation to ligands for } \\
\text { oncology }\end{array}$ & $\sim 70$ & $\begin{array}{l}\text { SC (p/n-type); anti-tumor } \\
\text { agent }\end{array}$ & PDT; CTX \\
\hline $\begin{array}{l}\text { Copper (II) oxide, } \\
\text { CuO }\end{array}$ & Powerful oxidizing agent & $\sim 100$ & $\begin{array}{l}\text { SC (p-type); anti-tumor } \\
\text { agent; weak FM }\end{array}$ & $\begin{array}{c}\text { PDT; CTX; RTX }\left({ }^{64} \mathrm{Cu},{ }^{62} \mathrm{Cu}\right) ; \\
\text { MB (via intracellular ROS); } \\
\text { PL }\left[22^{\mathrm{a}}, 23^{\mathrm{b}}\right]\end{array}$ \\
\hline $\begin{array}{l}\text { Gadolinium (III) } \\
\text { diamide or } \\
\text { chelates, } \mathrm{Gd}_{2} \mathrm{O}_{3}\end{array}$ & $\mathrm{~T}_{1} \mathrm{CA}$ & 80 & Toxic; PM & $\begin{array}{c}\text { Reduction of } \mathrm{T}_{1} \text { signal in MRI } \\
{\left[2^{\mathrm{c}}\right]}\end{array}$ \\
\hline Gold, $\mathrm{Au}(0)$ & $\begin{array}{l}\text { LSPR; PH agent; QD; con- } \\
\text { jugation to ligands for on- } \\
\text { cology }\end{array}$ & $<100$ & Optical tuning; DDN & $\begin{array}{l}\text { LSPR imaging; PH and PDT; } \\
\text { RTX (brachytherapy }{ }^{198} \mathrm{Au} \text { ) }\end{array}$ \\
\hline $\begin{array}{c}\text { Iron (III) oxide, } \\
\mathrm{Fe}_{2} \mathrm{O}_{3} \text {, iron (II/III) } \\
\text { oxide, } \mathrm{Fe}_{3} \mathrm{O}_{4}\end{array}$ & $\begin{array}{l}\text { Imaging agent; QD; USPIOs } \\
\text { / SPIOs }\end{array}$ & $5-150$ & $\begin{array}{l}\text { FM; SPM particles; dense } \\
\text { material; SC }\end{array}$ & $\begin{array}{l}\text { CA for MRI, US, SPECT, } \\
\text { PET; MH; stem cell tracking; } \\
\text { magnetic separation tech- } \\
\text { niques }\left[21^{\mathrm{d}}\right]\end{array}$ \\
\hline $\begin{array}{c}\text { Iron (II) oxide, } \\
\mathrm{FeO}\end{array}$ & $\mathrm{T}_{1} \mathrm{CA}$ & 25 & PM particles & Reduction of $\mathrm{T}_{1}$ signal in MRI \\
\hline $\begin{array}{l}\text { Manganese (II) } \\
\text { oxide, } \mathrm{MnO}\end{array}$ & $\begin{array}{l}\text { Conjugation to ligands for } \\
\text { oncology }\end{array}$ & $10-30$ & PM particles & CA for MRI; DDN in CTX \\
\hline $\begin{array}{l}\text { Platinum (IV) } \\
\text { chelates }\end{array}$ & $\begin{array}{c}\text { Cisplatinum-diamine dichlo- } \\
\text { ride in mPEG/PLGA poly- } \\
\text { mer }\end{array}$ & $130-160$ & Toxic & $\operatorname{CTX}\left[24^{\mathrm{e}}\right]$ \\
\hline Silver (0) & $\begin{array}{c}\text { Medical devices; biomedical } \\
\text { imaging }\end{array}$ & $1-100$ & $\mathrm{MB} ; \mathrm{DDN}$ & LSPR imaging; CTX \\
\hline
\end{tabular}

Key: ferromagnet (FM), superparamagnetic (SPM), paramagnetic (PM), local surface plasmon resonance (LSPR) semiconductor (SC), quantum dot (QD) nanoparticle, contrast agent (CA), reactive-oxygen species (ROS), small paramagnetic iron oxide (SPIO) - 60-150 nm, ultra-small paramagnetic iron oxide (USPIO) - 10-40 nm. Imaging techniques: magnetic resonance imaging (MRI), X-ray computed tomography (XCT), single photon emission computed tomography (SPECT), positron emission tomography (PET), ultrasound (US) and photo-luminescence (PL). Therapy types: microbial biocide (MB), drug delivery nanoparticle (DDN), chemotherapy (CTX), radiotherapy (RTX), (PDT), neutron capture therapy (NCT), magnetic hyperthermia $(\mathrm{MH})$ and photonic hyperthermia $(\mathrm{PH})$. Active-targeting or localized administration of encapsulated drug mean it can be released only at intended target site thus minimizing side-effects. Quantum dots are semiconductor particles with a size $\sim 1-10$ $\mathrm{nm} . \mathrm{T}_{1}$ and $\mathrm{T}_{2}$ are timed events for MRI imaging. References (a-e) are also cited in the text. 
illumination but are cumbersome and expensive and inapplicable to physiological internalization.

Juzenas et al. [1] provide a detailed description of quantum dots (QDs) and how their properties as photosensitizer and radio-sensitizer agents could make them useful as theranostic (therapeutic and diagnostic) agents [2] in cancer treatment. QDs are smaller in size than the exciton radius, which is an average distance between an electron and its hole when light absorption leads to excitation of an electron from the valence to the conduction band [14]. QDs exhibit the properties of a single molecule and the electron energy levels in QDs can be described as atomic orbitals and have been demonstrated to yield highly-reactive singlet oxygen $\left({ }^{1} \mathrm{O}_{2}\right)$ over 'conventional' triplet state oxygen $\left({ }^{3} \mathrm{O}_{2}\right)$, which can be useful in promoting cell apoptosis for destroying cancer cells [1, 7]. Surface plasmon resonance (SPR) or local surface plasmon resonance (LSPR) means certain materials permit oscillation of free electrons in the presence of light, such as to emit other energies of radiation in the form of light or heat [13]. QDs can be made to shift emission towards the red and near-infrared (NIR) region (especially 650-900 nm), which is useful for photothermal excision processes in medicine. Light emission due to QDs by LSPR is more reliable and consistent compared with organic compounds that show such properties, and this means particle based systems are highlyfavored. These oscillations are described by Takahashi et al. [14] who constructed dual silver and iron-cobalt ( $\mathrm{Ag} / \mathrm{FeCo})$ magneto-plasmonic hybrid NPs encapsulated in clathrin coated liposomes, as innovative tools to study cell biology and pathology. In contrast, direct medical use is demonstrated by plasmonic photothermal therapy when nanoparticle photonic 'triggering' by a NIR source laser was used in a recent study [30]. Unfortunately, the toxicity of many common semiconductor QDs (Cd, CdSe, CdAs, GaAs, etc) and other species makes their potential routine medical use rather implausible. Nevertheless, Lajunen et al. [31], Thanh et al. [32] and Locatelli et al. [33] have proposed QDs as ideal tools for studying and monitoring nanoparticle delivery at cellular and systemic levels while replacing QDs with other drugs in real applications in vivo.

The main imaging modes that are improved by incorporating metallic NPs are optical, magnetic resonance imaging (MRI), single photon emission computed tomography (SPECT), positron emission tomography (PET), computed tomography (CT) and ultrasound (US) imaging and drug delivery [34, 35], using theranostic nanoparticles [2]. Among these, optical imaging suffers from poor tissue penetration $(0-2 \mathrm{~cm})$, susceptibility to noise and background auto-fluorescence but that can be mitigated by NIR to some extent. However, MRI provides good spatial resolution but suffers from low sensitivity and requires administration of paramagnetic molecules such as gadolinium (Gd). This element has problems with slow excretion and long-term toxicity but may have a remedy in the encapsulation discussed by Kim et al. [20], involving gadolinium oxide nanoparticles. An alternative could be iron oxide NPs chemically 'tagged' on liposomes described in a study by Gopal et al. [4] that went on to explore chitosan-based copper nanocomposites (CCNC) in wound healing. Chitosan was chosen because of its biocompatibility and also by virtue of its wound healing properties that would work synergistically with copper ions. Chemically modified cellulose, known commercially as hypromellose (HPMC) is used in cosmetics, dissolving oral films and pharmaceutical tablets as a binding and structuring agent but provides a means of delivering and dosing the nanogel suspension and it is the intention in this research to investigate nanoparticle carryingmicelles entrapped in such gels. As part of this process is would be necessary to ensure entrapment of the metallic NP in the micelle.

Poloxamers are often used in state-of-the-art drug delivery systems due to their particular characteristics arising from a tri-block structure that consists of central hydrophobic polypropylene oxide (POP) chain and two side chains of hydrophilic polyethylene oxide (PEO). By varying the hydrophobic/hydrophilic chain length and ratio, poloxamers with different properties can be manufactured easily. Coupled with a biocompatible nature, poloxamers are ideal agents for encapsulating metal NPs given the ease of synthesis and engineering. Poloxamers at certain concentrations and temperatures spontaneously assemble into micelles, forming a hydrophilic shell and a hydrophobic core. These micelles have a narrow size distribution therefore, they offer advantages in the encapsulation of lipophilic or even insoluble drugs. The size of micelles can vary from 20 to $200 \mathrm{~nm}$, ensuring good penetration of blood vessels and long-lasting distribution in the body [36]. 
The surface of the metal NPs is positively charged and attracts polar molecules (e.g., water) and can be very reactive. To enable effective encapsulation in a hydrophobic micelle core, such a species would need to be functionalized by a lipophilic group, such as carboxylic acid, thiol, vinylpyrrolidone and other groups [32, 37, 38].

\section{MATERIALS AND METHODS}

\subsection{Materials Used}

\subsubsection{Gums, Purchased Nanoparticles and Sur- factants}

Benecel ${ }^{\circledR}$ E6 type: 2910 (product number: 424673, lot: 1458620, molecular weight $\mathrm{M}_{\mathrm{W}}$ 40000 (chemically known as low viscosity hydroxypropylmethylcellulose or hypromellose) and was obtained from Ashland Inc., USA. An aqueous dispersion of $2 \% \mathrm{w} / \mathrm{v}$ of Benecel ${ }^{\circledR}$ gives a viscosity of 4.8-7.2 mPas. Copper (II) oxide (CuO), $>99.95 \%$ purity, $\mathrm{M}_{\mathrm{W}} 79.5,25-55 \mathrm{~nm}$ nominal size, stock number: US3063, CAS: 1317-38-0, size $25 \mathrm{~g}$ ) was obtained from US Research Nanomaterials Inc., Houston, USA. The copper nanoparticles were degreased by successive rinses in solvents of diminishing lipophilicity (in the order: hexane, chloroform, ethanol, water). The inhibitory (toxic) concentration of copper for algal species is approximately $12 \mathrm{mgL}^{-1}$ [28]. Pluronic $\AA$ F68 Pastille (poloxamer $188 ; \mathrm{M}_{\mathrm{W}} 8400, \sim 80 \%$ ethylene oxide, HLB 32, product number: 412325, lot number: WPYY-647C) and Pluronic ${ }^{\circledR}$ F108 Prill (poloxamer 338; $\mathrm{M}_{\mathrm{W}} 14600, \sim 80 \%$ ethylene oxide, HLB $\sim 29$, product number: 583062, lot number WPMX534B) were obtained from BASF, USA. Sodium dodecyl sulfate ultrapure $\left(\mathrm{CH}_{3}\left(\mathrm{CH}_{2}\right)_{11} \mathrm{SO}_{4} \mathrm{Na}\right.$, $>99 \%$ purity, $\mathrm{M}_{\mathrm{W}} 288$, product number: 166-100, batch number: 16416, CAS 151-21-3) was obtained from Fisher Scientific, UK.

\subsubsection{General Reagents}

The majority of stock reagents were used in the study these were obtained from Fluka, SigmaAldrich, Fisher, and VWR. Anhydrous copper (II) sulfate $\left(\mathrm{CuSO}_{4},>99 \%\right.$ purity, $\mathrm{M}_{\mathrm{W}}$ 159.6, type: C/8600/50, lot: 1140130) used to make nanoparticles was obtained from Fluka, Germany. Sodium benzoate $\left(\mathrm{C}_{6} \mathrm{H}_{5} \mathrm{COONa}\right.$, a food/pharmaceutical fungicide and preservative (number E211) is used at concentrations of $<0.1 \% \mathrm{w} / \mathrm{v}$ in foods, $>99 \%$ purity, $\mathrm{M}_{\mathrm{W}}$ 144, type: A15946, lot: 10191620) was obtained from Alfa Aesar, England. Sodium ben- zoate has a $\log P$ value of 1.87 (solubility $690 \mathrm{mgL}^{-}$ ${ }^{1}$ ), indicating moderate lipophilicity and at $\mathrm{pH} 7$ in buffer the acid is $100 \%$ ionized $\left(\mathrm{p} K_{\mathrm{a}} \sim 4.2\right)$. The median toxicity for humans based on animal models and is moderate for copper sulfate ( $\mathrm{LD}_{50}$ (rat, oral) $\left.=300 \mathrm{mgkg}^{-1}\right)$ and low for benzoic acid $\left(\mathrm{LD}_{50}\right.$ (rat, oral) $=4100 \mathrm{mgkg}^{-1}$ ). Disodium hydrogen phosphate dihydrate $\left(\mathrm{Na}_{2} \mathrm{HPO}_{4} \cdot 2 \mathrm{H}_{2} \mathrm{O},>98 \%\right.$ purity, $\mathrm{M}_{\mathrm{W}} 178$ product: S/4440/65, lot: 0307261), sodium dihydrogen phosphate dihydrate $\left(\mathrm{NaH}_{2} \mathrm{PO}_{4} \cdot 2 \mathrm{H}_{2} \mathrm{O}\right.$, $>98 \%$ purity, $\mathrm{M}_{\mathrm{W}} 156$, product: $\mathrm{S} / 3720 / 65$, lot: 1285646 ), sodium hydroxide pellets ( $>98 \%$ purity, $\mathrm{M}_{\mathrm{W}}$ 40, type: 714695 , lot: $\left.433837 / 1\right), 5$ moldm $^{-3}$ nitric acid manufactured from concentrated nitric acid specific gravity (SG) $1.42(70 \% \mathrm{w} / \mathrm{v},>98 \%$ purity, $\mathrm{M}_{\mathrm{W}}$ 63, product: N/2250/PB17, lot: 1344248), hydrochloric acid SG $1.18(37 \% \mathrm{w} / \mathrm{v}$, $>98 \%$ purity, $\mathrm{M}_{\mathrm{W}} 36.5$, product: $\mathrm{H} / 1150 / \mathrm{PB} 17$, lot: 1674520), sulfuric acid SG $1.83(>95 \% \mathrm{w} / \mathrm{v},>98 \%$ purity, $\mathrm{M}_{\mathrm{W}}$ 98, product: S/9240/PB17, lot: 1538152) were all obtained from Fisher Scientific, UK. Potassium dichromate $\left(\mathrm{KCr}_{2} \mathrm{O}_{7},>99 \%\right.$ purity, MW 294, product: 26784.231, lot: 13D290030, AnanlaR NORMAPUR grade) was obtained from VWR, Belgium.

\subsection{Methods Used}

\subsubsection{Making and Using Ultra-purified Water}

Pure water was fabricated to a resistance of 18.2 $\mathrm{M} \Omega$, the surface chemically pure double deionized water $\left(\gamma=72.8 \mathrm{mNm}^{-1}\right.$ at $\left.20^{\circ} \mathrm{C}\right)$ produced was used in all experiments and rinsing operations. Purification of high grade deionized water via reverse osmosis and hydrophobe adsorption filters was undertaken on a Pure Lab Pulse 1/2 combined water purification system, ELGA, High Wycombe, UK.

\subsubsection{Contaminant Removal}

To aid removal of interfering grease, surfactants, polymers and metals all glassware were cleaned with sulfo-chromic acid, to remove trace contamination of surface-active and catalytic materials. The cleaning agent was prepared from a saturated solution of potassium dichromate in concentrated sulfuric acid. After several minutes of immersion all glassware used was rinsed exhaustively to $\mathrm{pH}$ neutrality with double deionized surface-chemically pure water. The glassware was then allowed to dry under ambient conditions in an inverted position at $25^{\circ} \mathrm{C}$. 


\subsubsection{Phosphate Buffer Universal Solvent and Dispersant}

All sample containing solutions were prepared in 0.05 moldm $^{-3}$ sodium phosphate buffer adjusted to $\mathrm{pH} 7.0$ unless otherwise stated [39]. To adjust the $\mathrm{pH}$ to exactly 7.0, a few drops of sodium hydroxide or hydrochloric acid were added at $25^{\circ} \mathrm{C}$.

\subsubsection{Synthesis of Coarse Copper Nanoparticles}

Synthesis of copper (II) nanoparticles was achieved by substituting the sulfate anion of finely ground cupric sulfate with sodium benzoate in a molar ratio of $1: 2$ to create a precipitate, which was filtered through a Sartorius $0.45 \mu \mathrm{m}$ PTFE filter unit in triplicate. The precipitate was filtered, sifted, graded and washed with copious amounts of deionized water and dried in an oven at $80^{\circ} \mathrm{C}$ over a period of a week so as to have a final dry particle size of $<450 \mathrm{~nm}$. To aid dispersal and prevent clumping for accurate sizing some copper (II) benzoate samples were prepared in 1 mmoldm $^{-3}$ SDS. The same fine near-spherical copper benzoate $(\mathrm{CuBz})$ particles were examined for their hydrophobicity using water contact angle measurements. Approximately, $0.3 \mathrm{~g} \mathrm{CuBz}$ powder in 50 $\mathrm{mL}$ of $1 \mathrm{mmoldm}^{-3} \mathrm{SDS}$ solution and its copper content were measured by using microwave plasma atomic emission spectroscopy and sizing by dynamic light scattering (DLS) at $25^{\circ} \mathrm{C}$.

\subsubsection{Surface Tension Measurements}

The surface tension was measured using the Wilhelmy plate method, which involves measuring the weight of an immersed glass plate in solution with a transducer. The surface tension was calculated by using an MS Excel spreadsheet written to measure dynamic surface tension based on appropriate calibration. Whenever possible, the measurement was performed in triplicate $(n=3)$ and the average value was used. The purpose-built apparatus was constructed from a combination of modular devices and software. These include a PowerLab ML826 analog-digital 2/26 converter (serial no. 226-0075), MacLab bridge amp (No. 2623) and PanLab (TR1202PAD) isomeric transducer (no. 727509), and Chart 5 (2006) software, ADInstruments, Australia. The custom built apparatus uses a replaceable plate fabricated from a $2 \mathrm{~cm} \times 2$ $\mathrm{cm} \times 0.1 \mathrm{~mm}$ microscope slide coverslip and holding loop-cemented onto the ground glass surface. Measurements were made at $20^{\circ} \mathrm{C}$ following a 15 minute equilibration period $[35,39]$.

\subsubsection{Contact Angle and Surface Hydrophobicity Measurements}

Dried precision-levelled $\mathrm{CuBz}$ powder was pressed with a hardened glass plate into a flat-bed pellet under $3 \mathrm{~kg} 100 \mathrm{~cm}^{-2}$ surface placed on a planar hardened glass support, to exclude all possible air cavities and present a flat uniform surface of sub-millimeter roughness. A $0.05 \mathrm{~mL}$ droplet of ultra-pure water was gently placed on the surface as a sessile drop and allowed to equilibrate for 10 minutes. Triplicate measurement $(n=3)$ of advancing $\left(\theta_{\mathrm{a}}\right)$ and receding contact angle $\left(\theta_{\mathrm{r}}\right)$ was made at $25^{\circ} \mathrm{C}$.

\subsubsection{Microscopy}

$\mathrm{CuO}$ and $\mathrm{CuBz}$ images undertaken in triplicate $(n=3)$, were captured with $\times 1$ or $\times 2$ zoom with a $3 \mathrm{~mm}$ aperture camera (picture quality $12 \mathrm{MPix}-$ els/field of view) linked to a Nikon Eclipse E200 MV RS (serial number: 105954) binocular light microscope (Japan) with magnification 40 times normal. Sizes were estimated by comparison $(n=$ 3) with a calibrated $25 \mu \mathrm{m}$ gold-plated tungsten wire (Luma Metall, Sweden) at $25^{\circ} \mathrm{C}$. The magnification of sample for measurement was provided by a $\times 40 /$ NA0.65 Plan ( $\infty / 0.17$ WD 0.65$)$ detachable lens also from Nikon.

The morphology and sizing of copper nanoparticles was studied using a high-resolution transmission electron microscope (TEM) with a JEOL JEM-2200FS (USA) operating at an accelerating voltage of $200 \mathrm{kV}$ with field emission gun. Aqueous samples were diluted 10-fold with distilled water and of $100 \mu \mathrm{L}$ having been $0.22 \mu \mathrm{m}$ filtered were deposited onto plasma-etched, carbonFormvar coated 200-mesh copper grids (Agar Scientific, UK). Once wick-uptake drying excess solution with filter paper was completed all the samples were allowed to further air dry. Equilibrated samples were then loaded under high vacuum into the TEM holder ready for measurement [19].

\subsubsection{Particle Size, Morphology and ל-potential Measurements}

Zetasizer ${ }^{\circledR}$ Nano ZS90 (model ZEN3690, serial no. MAL 1057082), Malvern Instruments, UK was used for Sauter average hydrodynamic diameter $\left(d_{3,2}\right)$ size measurements in the range $0.3-3000 \mathrm{~nm}$. As part of the dynamic light scattering technique, the Zetasizer provided the $z$-average value of the particle sizes of the particulates within the sample. 
Set to solvent refractive index 1.33 , solvent viscosity $1.0 \mathrm{mPas}(0.8872 \mathrm{cP})$, dispersant dielectric constant of 78.5 , measurement temperature $25^{\circ} \mathrm{C}$, polydispersity was customarily in the range 0.5 1.0 and the count rate per second was typically 30 $40 \mathrm{kcps}$, Estimates of size were based on an average of three measurement scans of 10 individual counts $(n=10)$. The scattering angle was set to $90^{\circ}$ from a laser tracking system of $0.1-1 \mathrm{~mW}$ power and wavelength of $830 \mathrm{~nm}$. Particle hydrodynamic diameter was measured using an approximation of Mie theory and the Stokes-Einstein equations written into the Zetasizer version 7.11 software, and particle surface charge ( $\zeta$-potential) was measured via the application of a variable potential ( \pm 5 volts; $\pm 5 \mathrm{~mA}$ current) and Smoluchowski approximation across three scans $(n=3)$, which was used for provision of the zeta-potential using the in-built anemometer [40, 41]. All samples were ultrasonicated for 3 minutes and filtered through a $0.45 \mu \mathrm{m}$ PTFE porous filter units prior to measurement. Sizing used a $1 \mathrm{~cm}$ path length four clear-windowed plastic cuvette (CXA-110005J UV grade cuvette, lot: 11388773), Fisher Scientific, UK whereas zeta-potential measurements required use of a polycarbonate folded capillary cell (product DTS10T0) from Malvern, UK.

\subsubsection{Metal Identification and Measurement by Atomic Spectroscopy}

A sample of $0.3 \mathrm{~g}$ of prepared $\mathrm{CuBz}$ (approximate stoichiometry $1: 2$, Cu:benzoate) was dispersed in $50 \mathrm{~mL}$ of $50 \mathrm{mmoldm}^{-3}$ sodium phosphate buffer at $\mathrm{pH} 7.0$; this represents a concentration of $6000 \mathrm{mgL}^{-1}$ or $6000 \mathrm{ppm}(\sim 0.0196$ $\left.\mathrm{mmoldm}^{-3}\right)$. After stirring for 10 minutes and followed by a standing time of 1 hour, $1 \mathrm{~mL}$ of the clear upper portion of the sample (vast majority) was diluted to $40 \mathrm{~mL}$ with phosphate buffer and sodium dodecyl sulfate (SDS) to a final SDS concentration of $1 \mathrm{mmoldm}^{-3}$. This was to ensure even and continued dispersal of the colloidal $\mathrm{CuBz}$ (total concentration $150 \mathrm{ppm}$ ). This formed the primary analytical sample and was used to estimate the concentration of colloidal matter in suspension. In addition, after decanting away the clear portion the sediment present was dried, resuspended and subjected to further assay for copper by microwave plasma-atomic emission spectroscopy (MP-AES) for the $\mathrm{CuBz}$ NPs without included Pluronic. This formed the primary analytical sample for the sedimented fraction. All other samples were estimated by difference between the measured suspended loads versus theoretical total copper included.

Approximately, $1.00 \mathrm{~mL}$ of the primary analytical sample suspension of either copper oxide or copper benzoate $(\mathrm{CuBz})$ were combined with 1 $\mathrm{mL}$ of concentrated nitric acid and diluted to 50 $\mathrm{mL}$ with deionized water and agitation then made up to a volume of $100 \mathrm{~mL}$. Microassay of copper concentration $(C)$ in solution performed in triplicate $(n=3)$, was estimated by an experimental setup using a 4100 MP-AES microwave plasma atomic emission spectroscopy system G8000A (serial number AU1302362), Agilent Technologies, USA. The intensity $(I)$ of light of a specific wavelength $\left(\lambda_{\max }=324.745 \mathrm{~nm}\right)$ is both indicative and informing of the concentration of atomic copper in solution. Samples were mixed with 5 moldm $^{-3}$ nitric acid to provide soluble versions of the inhouse manufacture $\mathrm{CuBz}$ or $\mathrm{CuO}$ nanoparticles for the purposes of analysis in an adaptation of a method describe previously $[19,42]$ at $25^{\circ} \mathrm{C}$. A calibration plot based on six-points, each an average of triplicate solutions $(n=3)$, using solutions of copper (II) sulfate in deionized water as a source of copper was used to establish a calibration plot to aid sample quantification.

\subsubsection{Polymer Rheology and Viscometry Meas- urements}

A Haake Rheostress ${ }^{\circledR}$ 1, type 397-001 rheometer, with build-in software, Thermo Scientific, Germany was used to assess gel texture. The apparatus was used with a $35 \mathrm{~mm}$ titanium cone type 35/1 (type: 01019). The apparent viscosity ( $\eta$ ) from stress-strain runs and the complex viscosity $\left(\eta^{*}\right)$, storage modulus $\left(G^{\prime}\right)$ and loss modulus $\left(G^{\prime}\right)$ were determined using an oscillatory measurement at an oscillation sweep frequency of $10 \mathrm{~Hz}$ and an imposed stress of $1.0 \mathrm{~Pa}[35,40]$. The oscillatory sweep featured sinusoidal deformation with different frequencies in Hertz to access the response of the sample towards deformation. Samples of approximately $1.0 \mathrm{~mL}$ containing $0.5 \%, 1.0 \%, 1.5 \%$, $2.0 \%, 2.5 \%$ and $3.0 \% \mathrm{w} / \mathrm{v}$ HPMC dissolved using a Fisherbrand ultrasonic water bath at $25^{\circ} \mathrm{C}$ were evaluated for the rheological and viscosity profiles of the hydrogels (viscous syrups) formed in the cone and plate apparatus at $25^{\circ} \mathrm{C}$. 


\section{RESULTS AND DISCUSSION}

\subsection{Interfacial and Micellar Properties of Sur- face-actives}

Fig. (1) shows the interfacial tension for two non-ionic polymeric surfactants, Pluronics and a simple anionic surfactant, SDS. The critical micelle (or aggregation) concentrations were found to $1 \times 10^{-2}$ mmoldm $^{-3}, 2.5 \times 10^{-2}$ mmoldm $^{-3}$ and 1 mmoldm ${ }^{-3}$, for F108, F68 and SDS, respectively. This difference in micellization is driven by the difference in hydrophile-lipophile balance (HLB) between the polymers (HLB 16) and the very much more water-dispersible SDS (HLB 40). However, interfacial loading and therefore higher micelle packing, evidenced in lower equilibrium surface tensions and lower surface free energies and efficiency of surface tension reduction mean the equilibrium surface tensions for Pluronic F108 $\left(\mathrm{M}_{\mathrm{W}}\right.$ 14600), Pluronic F68 $\left(\mathrm{M}_{\mathrm{W}}\right.$ 8400) and SDS $\left(\mathrm{M}_{\mathrm{W}} 288\right)$, which are surfactant of decreasing molecular mass were 48, 50 and $30 \mathrm{mNm}^{-1}$, respectively. The distinction in surface tension between two types of surfactant is indicative of interfacial packing efficiency [35], which is much better for small low molecular weight surfactants. Importantly at concentrations of higher than 0.1 mmoldm $^{-3}$ only micelle NPs should exist in the aqueous sample of the Pluronics.

Difficulties in the determination of CMC for sodium dodecyl sulfate (SDS) are explained by Umlong and Ismail [42] as being due to the additional surfactant effect of dodecyl alcohol, which is present in the solution either as an impurity in the reagent or by it being produced in the solution by SDS hydrolysis. Corrin and Harkin [43] have a theoretical prediction of $\mathrm{CMC}$ for SDS of 1.9 mmoldm $^{-3}$, which is close to the CMC estimated in Fig. (1). Two pluronics were selected on their hydrophilicity but also possess an ability to adsorb and bind components. Pluronic F68 (Poloxamer $188)$ a short polymer $\left(\mathrm{M}_{\mathrm{W}} 8400\right)$ with high water dispersibility (81.8\% ethylene oxide (EO) and $18.2 \%$ propylene oxide (PO) residues) routinely achieves equilibrium surface tensions $\left(\gamma_{\mathrm{eq}}\right)$ of $\sim 50$ $\mathrm{mNm}^{-1}$ and micelle hydrodynamic diameters of approximately $10 \mathrm{~nm}$, suggesting chain length is 1.2-1.8 nm [15, 16]. Pluronic F108 (Poloxamer 338) a longer polymer $\left(\mathrm{M}_{\mathrm{W}} 14600\right)$ also with high water dispersibility (83.8 \% EO and 16.2\% PO residues) additionally, routinely achieves equilibrium surface tensions $\left(\gamma_{\mathrm{eq}}\right)$ of $\sim 41 \mathrm{mNm}^{-1}$ and its micelle hydrodynamic diameter and chain length size is in accordance with those of related compound F68. In the presence of different solutes, their polarity, HLB, partitioning coefficient $(\log P)$ and interaction with surfactant molecules, as well as poloxamer composition, the extension length of polyoxypropylene (PPO) and polyoxyethylene (PEO) chains, can change the observed CMC, sometimes substantially [16]. Tensiometric measurements found that the CMC for Pluronic F108 in a phosphate buffer was close to the $\mathrm{CMC}$ value in water solution as stated by Alexandridis et al. [45]. According to the same authors it appears that electrolytes, such as sodium and phosphate ions, have little or no effect on micelle formation with F108 as in the case of the Pluronics investigated in this work. Pluronic F68 and F108 are ideal polymers to use for encapsulation because of their biocompatibility, with a very low lethal dose of $50 \%$ of recipient toxicity $\left(\mathrm{LD}_{50}\right)$, with values of $\mathrm{LD}_{50}$ (rat, oral) of $1200 \mathrm{mgkg}^{-1}$ and $>2000 \mathrm{mgkg}^{-1}$, respectively [44].

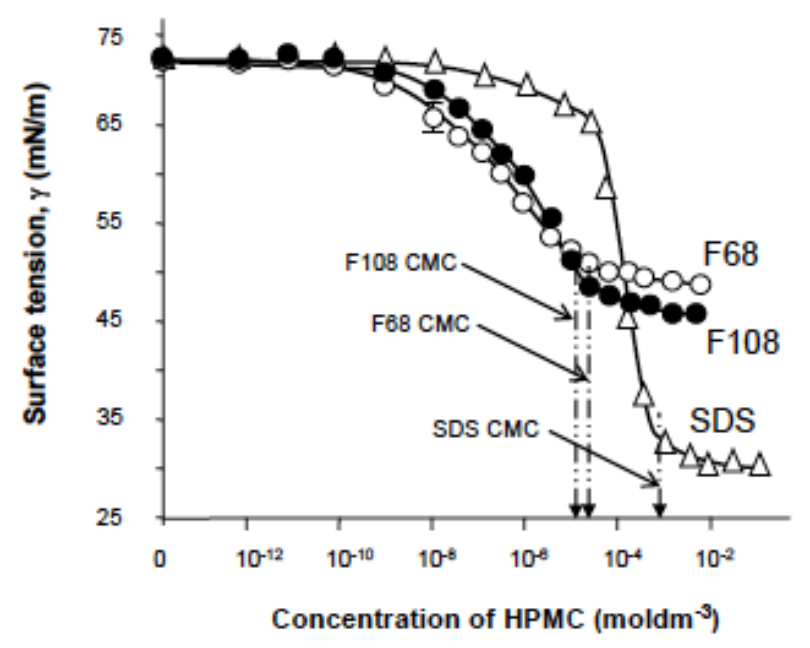

Fig. (1). Air-water $(A / W)$ surface tension profiles of two poloxamer (Pluronic F68 and Pluronic F108) surfactants measure by the Wilhelmy plate method. The profile for a non-polymeric surfactant, sodium dodecyl sulfate (SDS) is included for comparison.

\subsection{Micelle and Soft Matter Assembly Charac- terization}

Fig. (2) shows the mean micelle hydrodynamic diameter for F108, F68 and SDS of 42, 43 and 6 $\mathrm{nm}$ at concentrations of $50 \mathrm{mmoldm}^{-3}$, which at this higher concentration are higher for the polymers than reported previously $[15,42,46]$. However, at $0.01 \mathrm{mmoldm}^{-3}$ the particle size of the 
Pluronic was approximately 22 and $11 \mathrm{~nm}$ for F108 and F68, respectively. At low concentrations this latter size probably relates to a monomeric species or minor structure, whereas at $50 \mathrm{mmoldm}^{-}$ 3 well above their CMC the polymers show a reproducible size of two- to four-fold the size of simpler structures. The smaller, more compact size of the F68 micelle over the F108 micelle is probably related to the, shorter persistence length of the molecule, increased hydrophobicity of the moiety and tighter micelle (an surface lateral) packing efficiency of F68, as indicated by elsewhere [44, 45] and experimentally determined surface tensions (Fig. 1). Notably, the SDS micelle was approximately half the diameter of the F68 micelle formed from the low concentration Pluronic solutions. The SDS micelle size is confirmed at $6 \mathrm{~nm}$, as the molecule has a molecular length of 2-3 $\mathrm{nm}$ [42]. The $\zeta$-potentials for the poloxamers nanoparticles and the SDS micelle are given in Fig. (3). The surface charge of the SDS micelle is approximately 35 times that of the non-ionic poloxamers micelles of F68 and F108 at a value of $-70 \mathrm{mV}$. The small negative charge on the Pluronic micelles is probably associated with counterion adsorption from the buffer in which they were dispersed $[15,16,47]$ but the standard deviation values hint at notable variation that there could range from marginally neutral through to zero (and possibly to marginally positive) surface potentials. The signage of the charge suggests that associated hydroxyl, phosphate and hydrogen phosphate anions lie behind the charge associated with the non-ionic polymer surfactants in micelle form.

\subsection{Hydrophobing of Nanoparticles}

Encapsulation success in micelles depends on the entrained nanoparticle species size being less than that of the micelle but also importantly on surface lipophilicity. Lipophilicity of a drug is usually expressed as the logarithm of the partition coefficient $(\log P)$, a ratio of the partitioning concentrations of a drug between octanol and water. Another way to characterize lipophilicity is by determining wettability by measuring the contact angle at which, a liquid-vapor interface meets the solid surface. The contact angle is the result of three different interfacial tensions, which are, $\gamma_{\mathrm{SV}}-$ solid-vapor, $\gamma_{\mathrm{SL}}-$ solid-liquid and $\gamma_{\mathrm{LV}}$ - liquidvapor, and the relationship is described by Young's equation:

$$
\gamma_{\mathrm{LV}} \cos \theta=\gamma_{\mathrm{SV}}-\gamma_{\mathrm{SL}}
$$

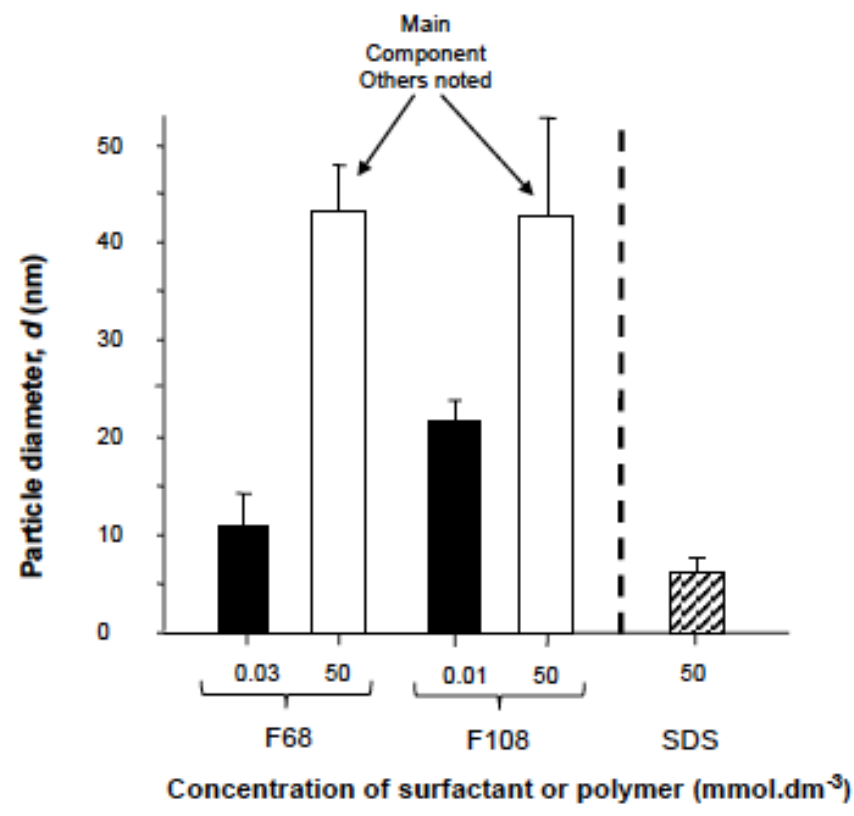

Fig. (2). The mean surface average diameter $\left(d_{3,2}\right)$ sizes of Pluronic F68 (poloxamer 188) and Pluronic F108 (poloxamer 338) polymeric micelles and SDS simple micelles measured by dynamic light scattering (DLS) using photon correlation spectroscopy (PCS).

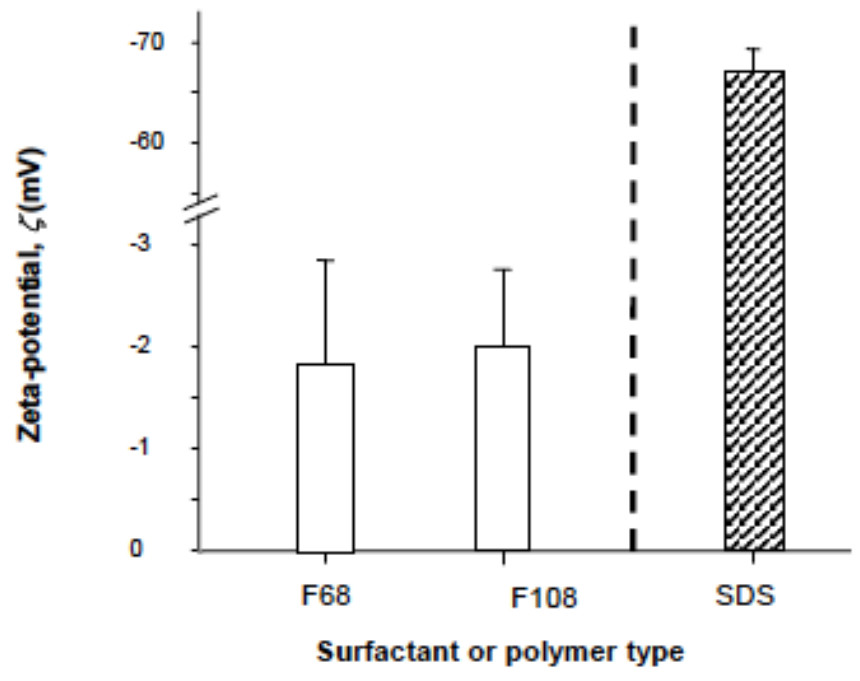

Fig. (3). The surface charge ( $\zeta$-potential) of Pluronic F68 (poloxamer 188) and Pluronic F108 (poloxamer 338) polymeric micelles and SDS simple micelles formed from $50 \mathrm{mmoldm}^{-3}$ solutions and measured by laser Doppler anemometry.

Conventionally, if the contact angle, $\theta$ is $<90^{\circ}$, the surface is considered hydrophilic, and $\theta>90^{\circ}$ is hydrophobic, or lipophilic [48]. The measurement of the contact angle by putting a small water drop on flat layer of solid powder seems simple and straightforward but in practice is an approximation 


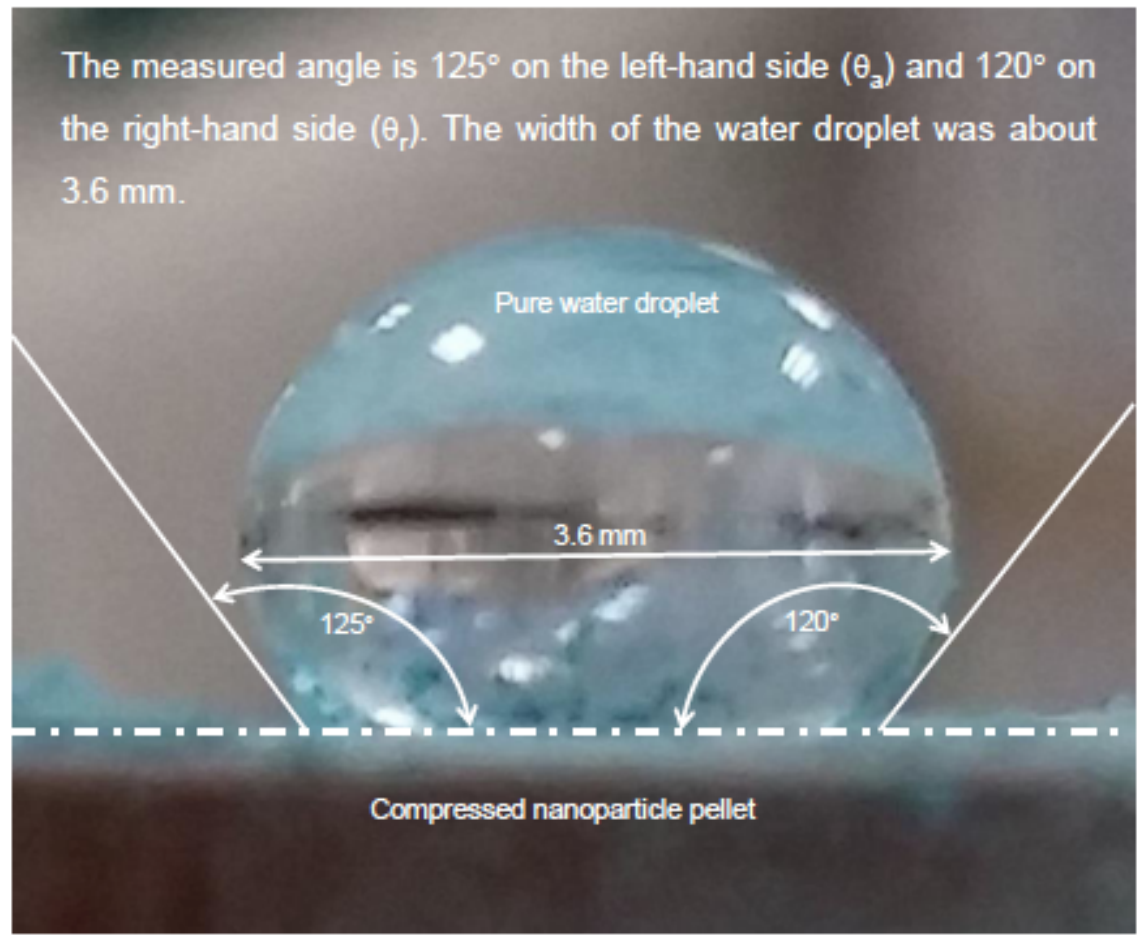

Fig. (4). Measurement of particle surface hydrophobicity determined by the pure water $\left(\gamma=72.8 \mathrm{mNm}^{-1}\right)$ contact angle $(\theta)$ on a compressed powder-pellet formed from copper nanoparticles derivatized with sodium benzoate.

that is due to introduced heterogeneity as a consequence of surface imperfections, impurities, surface topological heterogeneity, solubility of solid, inclusion of small air spaces, liquid evaporation and hysteresis, or several metastable states, which give a range of apparent contact angles [49]. Firstly, the solid surface may not be completely level or planar, which will cause the drop to move forming the advancing and trailing edge angle. The measured contact angle at the leading edge is called the advancing contact angle $\left(\theta_{\mathrm{a}}\right)$, and at the other edge it is referred to as the receding contact angle $\left(\theta_{\mathrm{r}}\right)$. Secondly, the surface roughness will cause a difference between the apparent contact angle and the actual contact angle. The actual angle, measured where a dip in the surface occurs is actually greater than apparent as the drop surface lies parallel to the solid surface but perhaps not seen by the resolution of the captured image.

Contact angle and pure water wettability on copper benzoate NPs is presented in Fig. (4). The contact and was measured repeatedly (triplicate) as $122.5^{\circ}$. This suggests the copper NPs had a hydrophobic coating as the contact angle was greater than the indicative reference value of $90^{\circ}$. As suggested above, a somewhat arbitrary classification means contact angles below this value point to a more hydrophilic (water or polar molecule wettable) surface and above $90^{\circ}$ are typical of more hydrophobic (less water wettable) surfaces. Similar contact angles to the $\mathrm{CuBz}$ surface were found experimentally using an identical approach for the following low surface energy or 'hydrophobic' substances, polyethylene $\sim 95^{\circ}$, polypropylene $\sim 100^{\circ}$, solid paraffin $\sim 109^{\circ}$, PTFE $\sim 110^{\circ}$ and polyisobutylene rubber $\sim 112^{\circ}$ (results not shown). The literature values for water repellent surfaces such as carnauba wax-sub-micron beaded PTFE covered planar surfaces and water contact angles of $130^{\circ}$ are well documented [50]. In supplementary studies (also not shown), a linear regression covering 10 solid polyolefin polymers and aliphatic wax-like solid materials $(n=3)$, was obtained, where contact angle, in degrees $(\theta)=(4.25$ $\times \gamma_{\mathrm{SV}}$ ), with $\gamma_{\mathrm{SV}}$ being the solid-vapor surface tension $\left(\mathrm{mNm}^{-1}\right)$. The fit despite showing some data scatter had an acceptable, correlation coefficient $\left(R^{2}\right)$ of -0.83 . Using this simple model it is possible to predict the solid-air surface tension for the $\mathrm{CuBz}$ to be $\sim 28.8 \mathrm{mNm}^{-1}$. On a similar scale a well-documented hydrophobic material such as PTFE as a solid is reported to have a $\gamma_{\mathrm{SV}}$ value of $\sim 23 \mathrm{mNm}^{-1}$ [51]. This finding is entirely congruous with the oily 'hand-feel' of the copper benzoate. The method of characterization used here is 
sleek and convenient however, discrepancies in the exactness of method render direct comparison with more theoretically sound measurements of contact angle or surface energy unsuitable. Differences between the two may be associated with microstructural effects and surface defects with a direct approach of experimentation versus a predictive approach $[50,51]$.

The hysteresis effect seen with the microheterogeneous surfaces tested in Fig. (4) is thought to be the cause of many observed advancing and receding contact angles as the drop has to overcome an energy barrier to move to the lowest energy. To overcome this effect Andrieu et al. [52] suggested applying a 'levelling' vibration to the system to overcome metastable energy levels and to take measurements only when the drop was sufficiently symmetrical. They also found that the final contact angle can be calculated by using the following averaging equation:

$$
\cos \theta=1 / 2\left(\cos \theta_{\mathrm{a}}+\cos \theta_{\mathrm{r}}\right)
$$

Using this equation allowed calculation of the estimated contact angle for copper benzoate NPs as consistently reproducible $122.47^{\circ}$. This value is very close to simple averaging values $\left(122.54^{\circ}\right)$ as suggested by Decker et al. [53]. It is therefore, evident that $\mathrm{CuBz}$ is 'lipophilic' and subsequently represented a sound potential candidate for encapsulation in polymer micelles. Having a $\log P$ of sodium benzoate of 1.9 indicates moderate lipophilicity (identical in magnitude to ethyl butyrate, a short aliphatic molecule) and this contrasts with the negative values of about -1.04 for the poloxamers. This value represents a mix of values attributed to a large number of ethylene oxide (EO) and propylene oxide (PO) substituents. However, The individual PO moiety of the $\left[-(\mathrm{EO})_{x}-(\mathrm{PO})_{y^{-}}\right.$ $\left.(\mathrm{EO})_{z^{-}}\right]_{n}$ poloxamer has a predicted $\log P$ value of $\sim 0.01$ to 0.03 (the individual EO moiety is $\sim-0.1$ to -0.3) meaning a much less water dispersible character, where more hydrophobic species would tend to congregate in the vicinity of this component $[16,33,35,45]$, particularly where burying, clustering and hydrophobic effect-driven association take place within the micelle core.

\subsection{Encapsulation and Soft Matter-hard Mat- ter Composites}

The particle size and copper content of nanoparticles is presented in Fig. (5). Bare in- house manufactured $\mathrm{CuBz}$ particles were found to be approximately $185 \mathrm{~nm}$ in diameter $(195 \mathrm{~nm}$ when covered with SDS). This suggests the SDS coating and associated water was $10 \mathrm{~nm}$ (or $2 \times$ $5 \mathrm{~nm}$ ). Whereas, the same particles were measured as being $310 \mathrm{~nm}$ for $34 \mathrm{mmoldm}^{-3}$ to $615 \mathrm{~nm}$ and over $630 \mathrm{~nm}$ for 68 and $136 \mathrm{mmoldm}^{-3} \mathrm{~F} 108$, respectively. The standard deviation for most F108CuBzNP sizing is in the range $\pm 10-20 \mathrm{~nm}$, suggesting a variety of forms of the aggregate. The explanation for this large increase over the bare $\mathrm{CuBz}$ NPs lies in the network of surfactant chains forming a supramolecular assembly facilitated by the Pluronic. Fig. (5) also shows that $\mathrm{CuBz}$ nanoparticles as being less flocculated in the presence of SDS or polymeric emulsifier. Indeed, SDS was used for all AES analyses on recovery of the sample supernatant because using a surfactant aided dispersal. The supernatant was found to contain more copper in the presence of $0.1 \mathrm{mmoldm}^{-3}$, $1 \mathrm{mmoldm}^{-3}$ and $10 \mathrm{mmoldm}^{-3} \mathrm{SDS}$ indicating its encapsulation (results not shown); with the 1 mmoldm ${ }^{-3}$ sample having the optimum dispersal and representing the most practical ionic strength for passing through the AES apparatus.

In roughly equivalent terms, a $1.0 \mathrm{~mL}$ aliquot of a resuspended sedimented fraction of the $\mathrm{CuBz}$ NPs in buffer alone, was found to contain, as expected much more copper in the "flocculated mass" at the base of the vessel (122 ppm measured versus $120 \mathrm{ppm}$ theoretical) than in the same portion in the presence of dispersant polymer, typically 142-143 ppm (Fig. 5). In the experimental set up the total amount of dispersed copper benzoate NPs in the aliquot taken for analysis was 150 $\mu \mathrm{gmL}^{-1}$ or $150 \mathrm{ppm}$. The theoretical values are presented for sedimented copper benzoate and the experimentally determined values for colloidal $\mathrm{CuBz}$ in Fig. (5). Without using the AES equipment to measure the residue in this manner it is possible to deduce the proportion of non-dispersed material and the efficiency of the poloxamer 338 (larger Pluronic F108 species) as a dispersing agent based entirely on the subtraction of total copper minus suspended colloidal copper measured. Without surfactant approximately $20 \%$ of the NPs were suspended, with $80 \%$ flocculated. However, between 68-136 $\mu_{\text {moldm }}^{-3}$ F108 included 95.4-96.0\% was suspended with a mere $4-4.6 \%$ remaining in the undispersed $\mathrm{CuBz} \mathrm{NP}$ sediment. Using nitric acid proved to be an ideal means of producing copper nitrate solution for measurement 


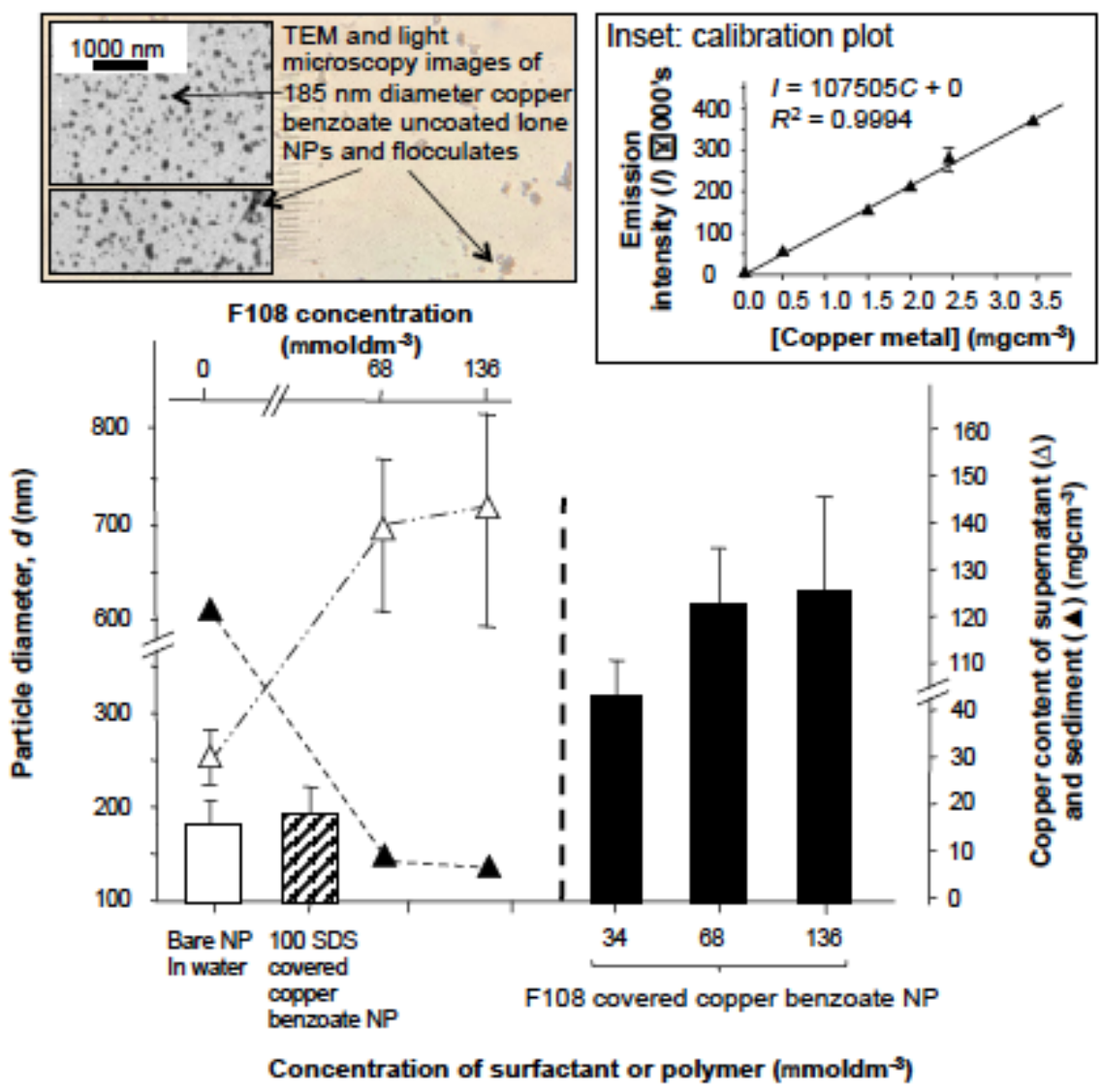

Fig. (5). Crude test-of-principle "large $(\sim 185 \mathrm{~nm})$ " nanoparticle copper benzoate nanoparticles and micelle encapsulation data for F108 nanogel beads. Size profiles $\left(d_{3,2}\right)$ and copper determination (inset: copper calibration plot) of the suspended fraction of the laboratory-synthesized copper nanoparticle (NP) samples are presented in the Figure along with transmission electron microscope (TEM) and light microscope image of solitary NPs and NP aggregate flocculates.

of either supernatant or subnatant of the $\mathrm{CuBz}$ colloidal suspensions. Particles of $\mathrm{CuBz}$ with larger hydrodynamic diameters, and there was some polydispersity to the $\mathrm{CuBz}$ sample indicated in Fig. (5), which were unable to remain suspended and following Stokes' Law sediment under the standard conditions.

To achieve a reproducible particle size commercial copper (II) oxide nanospheres (demonstrated in the photograph in Fig. 6) were used as the architectural scaffold in soft matter-hard matter molecular suprastructure fabrication. The topdown method of making NPs is by grinding, milling, shearing, which requires complicated equipment. However, a simple method of making NPs is by grinding them in a mortar with a pestle [54] as used for the samples in Fig. (5). The drawbacks of this process is that the yield is low, the particle size will be of a very wide ranging nature, particles may be driven to agglomerate again and in addition, not all solids can be easily ground this way. Vigorous grinding of $\mathrm{CuBz}$ for about 15 minutes was needed and this becomes unfeasible. Interestingly, the 'course' synthesized powder obtained appeared slightly "wax-like" in consistency. $\mathrm{CuBz}$ was found to be moderately hydrophobic as confirmed by contact angle measurements, and thus the powder tends to be poorly water dispersible, adhere to the water surface, for which necessitated active-stirring for 10 minutes. Alternatively the technique could have used sonication to improve better dispersion of fine particles in water. The mixture was exceptionally polydispersed despite the grading practices and filtration employed and so, potentially some improved simple filtration method is needed to separate NPs of certain range for large scale production, for example, using ultrathin silicon membranes with approximate pore sizes ranging from $5 \mathrm{~nm}$ to $25 \mathrm{~nm}$ show promise for separation of NPs of quite small sizes [55]. 

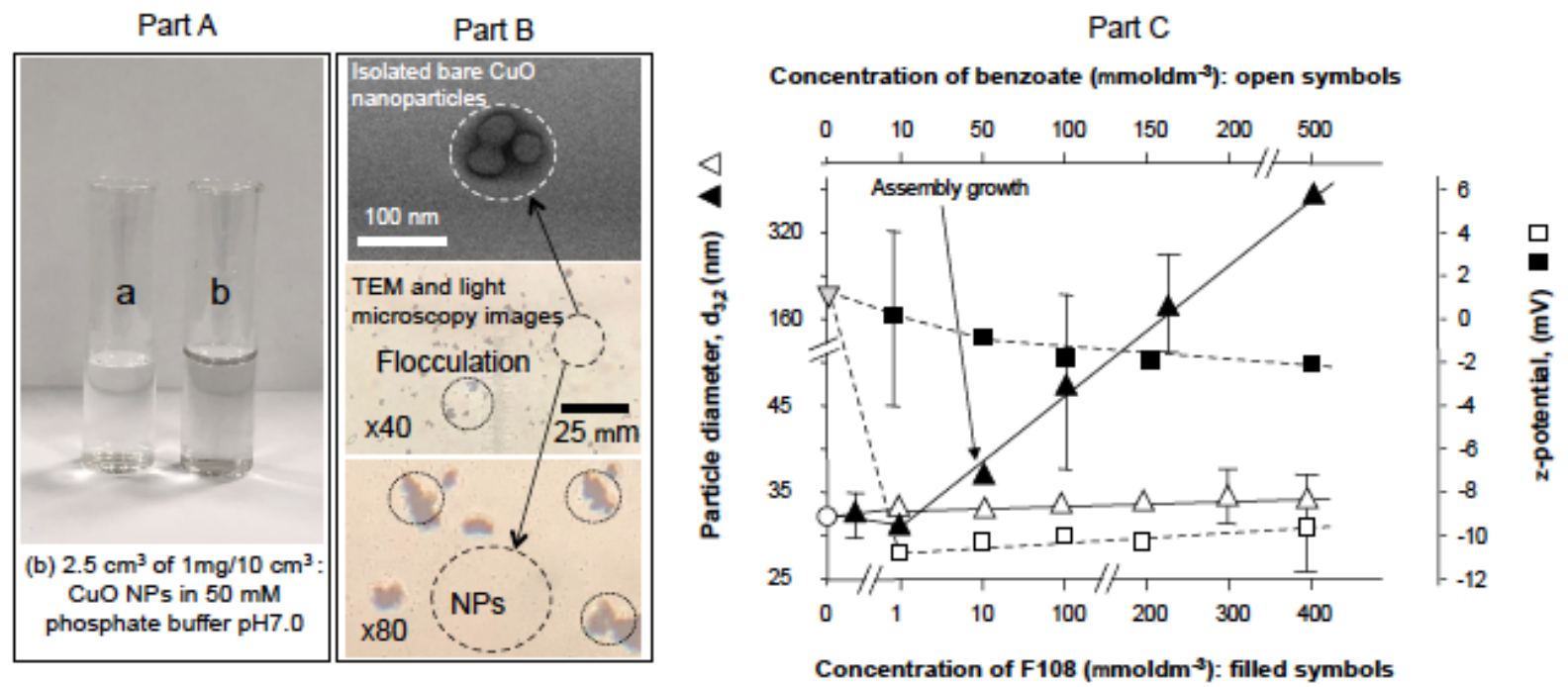

Fig. (6). Complex figure with three parts - Part A: Photograph of clean water (a) and phosphate buffered water with $30 \mathrm{~nm}$ colloidal $\mathrm{CuO}$ nanoparticles (b). Part B: Transmission electron microscope (TEM) and light microscope images of $\mathrm{CuO}$ nanoparticles and flocculated particle clusters at two magnifications. Part $\mathrm{C}$ : Chemical modification of homogeneously-sized commercial $30 \mathrm{~nm}$ copper oxide $(\mathrm{CuO})$ nanoparticles and their encapsulation within a Pluronic F108 $(\log P \approx-1)$ layer built on a sodium benzoate-derivatized surface or benzoate $(\log P \approx 1.9)$ 'blanket' alone. The triangles represent size data, with the inverted triangle representing the $\mathrm{CuO}$ alone and squares represent $\zeta$-potential, with the open circle representing the $\mathrm{CuO}$ alone.

Dispersal and subsequent $\mathrm{CuBz}$ nanoparticle stabilization was achieved with SDS solution. The hydrophobic tails of SDS molecules are attracted to hydrophobic $\mathrm{CuBz}$ particles, while the negatively charged heads form an outer layer providing repulsive forces maintaining particle separation. Dutta and Dolui [56] have reported the stabilization of synthesized $\mathrm{CuS}$ nanoparticle dispersion in SDS solution. They found that $2 \% \mathrm{w} / \mathrm{v}$ SDS provided stabilization for at least 210 days, whereas in SDS below the CMC, the particles eventually precipitated-out when the average particle size was $\sim 80 \mathrm{~nm}$. However, transmission electron microscopy (TEM) showed some particle aggregation even at the higher SDS concentration. Furthermore, measuring particle size in pure added F108 with DLS, produced peaks $>600 \mathrm{~nm}$, indicating the formation of large aggregates or assembly-like structures as suggested by Almgren et al. [57]. This is important because the expected theoretical $\mathrm{CuBz}$ solubility at $25^{\circ} \mathrm{C}$ is $0.43 \mathrm{mmoldm}^{-3}$, which equates to $0.027 \mathrm{gL}^{-1}$ of pure copper or $27 \mathrm{ppm}$. The experimental value with a $450 \mathrm{~nm}$ pore size filtered pure $\mathrm{CuBz}$ colloidal solution using MPAES measurements was $32 \mathrm{ppm}$ suggesting that most of the excess 5 ppm copper content in SDS stabilized dispersion was due to $\mathrm{CuBzNP}$. This was further confirmed by DLS measurements that showed peak at $185 \mathrm{~nm}$ and therefore, can be safely assumed to contain at least some $\mathrm{CuBz}$ particles within the nanometer range. It is believed that this $\mathrm{CuBz}$ dispersion is ultimately unstable in the short-term (day timescale) because of van der Waals forces of attraction exceeding those of electrostatic repulsion.

An ideal encapsulating micelle system should provide high loading capacity, high compatibility between the 'drug' (species) and encapsulating surfactant, appropriate size $(10-100 \mathrm{~nm})$, physicochemical stability in storage and the body, but also the possibility of inducing drug/species release when desired [58]. It is technically difficult and practically challenging to achieve all properties in one system. One issue with the experimental work presented in Fig. (5) is that the average $\mathrm{CuBz}$ particle size (hydrodynamic diameter) was $185 \mathrm{~nm}$, which is much greater than the literature F108 micelle diameter in a water solution of $\sim 12 \mathrm{~nm}$ [59], whereas, the measured value in this work was $22 \pm$ $3 \mathrm{~nm}$ (shown in Fig. 2). The discrepancy in size may be related to the purity and compounded by the polydispersity of the poloxamer 338 used. It is known, however, that the aggregation number and particle size, respectively, are dependent on temperature, ionic strength, $\mathrm{pH}$, co-polymers, and en- 
capsulated 'drug' and encapsulation method [31]. Careful attention to metal nanoparticle encapsulation when functionalizing metal NPs and selecting certain ligands is also crucial since many suitable ligands and surfactants (aerosol OT, picric acid, oxalic acid, etc) may be undesirable due to toxicity or interactions with other components that need to be co-encapsulated $[6,8,32,47]$.

Another way to improve $\mathrm{CuBz}$ encapsulation in polymer-based micelles nanogels is by crosslinking micelle core chains by UV radiation or by using species with bifunctionality covalently bound to a polymer core $[33,35,58]$. Alternatively, short-term micelle stability can be advantageous in cases when quick active release is required or quick excretion is sought. Such chemical maneuvering, is complicated, as making functionalizing polymers more chemically "sticky", may in fact promote flocculation and thus, precipitation. Adsorbed polymer can cause steric stabilization effects to some extent, whereas non-adsorbed polymer can induce the attraction of larger particles through the so-called depletion interaction [60], which is a theory originally developed by Asakura and Oosawa [61]. This theory explains that in the presence of polymer osmotic pressure, an exclusion zone is created around colloidal particles that can be preferentially occupied by two larger particles and in doing so causes disruption to the system and a subsequent increase in entropy (increased stability). This basic model is elegantly refined and updated by Trokhymchuk and Henderson [61]. Complex bridging interactions are also possible when polymers attach to the surface of more than one particle. In the case of increasing poloxamer concentration to $68 \mu_{\text {moldm }}{ }^{-3}$, particle size increase is even more dramatic, reaching $615 \mathrm{~nm}$, which seems to confirm and point at bridging flocculation. However, at a F108 concentration of $136 \mu \mathrm{moldm}^{-3}$, particle size was augmented slightly to $630 \mathrm{~nm}$. It is noteworthy that the size and shape of CuBzNPs are likely to be very heterogeneous and the average diameter value does not provide clear description of actual state of the system in terms of dispersal of solid within the soft matter assembly. Generally, this increase could be due to surface loading or packing (pancake, brush, monolayer or multilayer) or 'condensation' of larger particles to a larger entity. Similar stabilization events with a size increase were noticed by researchers who explored stabilization of iron NPs with the polysaccharide, guar gum [62]. A further increase of F108 concentration to $272 \mu$ moldm $^{-3}$ (not shown in Fig. 5) made the system 'unstable' with respect to consistent $\mathrm{CuBz}$ dosing with formation of large sized $\sim 10 \pm$ $70 \mathrm{~nm}$ aggregates, possibly due to particle and F108 interaction that caused flocculation, as seen elsewhere [42, 46]. There are other methods that could potentially be used to clarify the results, for example, small angle X-ray spectroscopy (SAXS), small-angle neutron scattering (SANS), which could clarify spatial resolution of CuBzNP and F108 molecule structuring but these fall outside the scope of this research.

The size in terms of the hydrodynamic diameter of colloidal copper oxide $(\mathrm{CuO})$, either bare (Fig. 6, Parts $\mathrm{A}$ and $\mathrm{B}$ ), coated with benzoate anions or covered with a sheath of adsorbed Pluronic F108, adsorbed onto benzoate covered $\mathrm{CuO}$ is shown in Fig. (6) (Part C). The $\mathrm{CuO}$ NPs were visualized as approximately spherical as shown in the photograph in Fig. (7). Previous work with $30 \mathrm{~nm}$ nanoparticles was undertaken with copper (II)phthalocyanine species where adsorption lead to a selective oxidative reaction with hydrocarbons that were in direct contact with the metal surface through physisorption highlighted the complexity of the wetting and surface coverage process [5]. The $30 \mathrm{~nm}$ sized bare $\mathrm{CuO}$ particles used here showed a little increase in diameter with adsorbed benzoate and also with adsorbed Pluronic also via physisorption up to a concentration of $10 \mu_{\text {moldm }}^{-}$ 3 concentrations. However, the diameter with associated water 'blanket' approximately doubled on a tenfold increase in poloxamers from 10 to 100 $\mu_{\text {moldm }}{ }^{-3}$, showed a five-fold increase at 200 $\mu_{\text {moldm }}{ }^{-3}$ and a more than 13-fold increase when including $400 \mu_{\text {moldm }}^{-3}$ F108. In parallel, the surface charge on inclusion of higher concentrations of adsorbate also changed from a $\zeta$-potential of bare $30 \mathrm{~nm}$ NPs of $2 \mathrm{mV}$ to approximately -0.5 $\mathrm{mV}$ with Pluronic F108 and $-8 \mathrm{mV}$ on inclusion of benzoate anions. Again as with earlier experiments looking at micelles, with associated F108, samples showed a small negative $\zeta$-potential. However, a reduction in surface potential occurred over a range of 0.5 to $400 \mu_{\text {moldm }}{ }^{-3}$ F108 and 6-500 $\mu$ moldm ${ }^{-3}$ benzoate irrespective of the actual concentration of the adsorbing material over these ranges, which is synonymous with either charge screening or counterion sequestration [63]. Securing of charges does appear to take place in the adsorbing anion or non-ionic species since the 

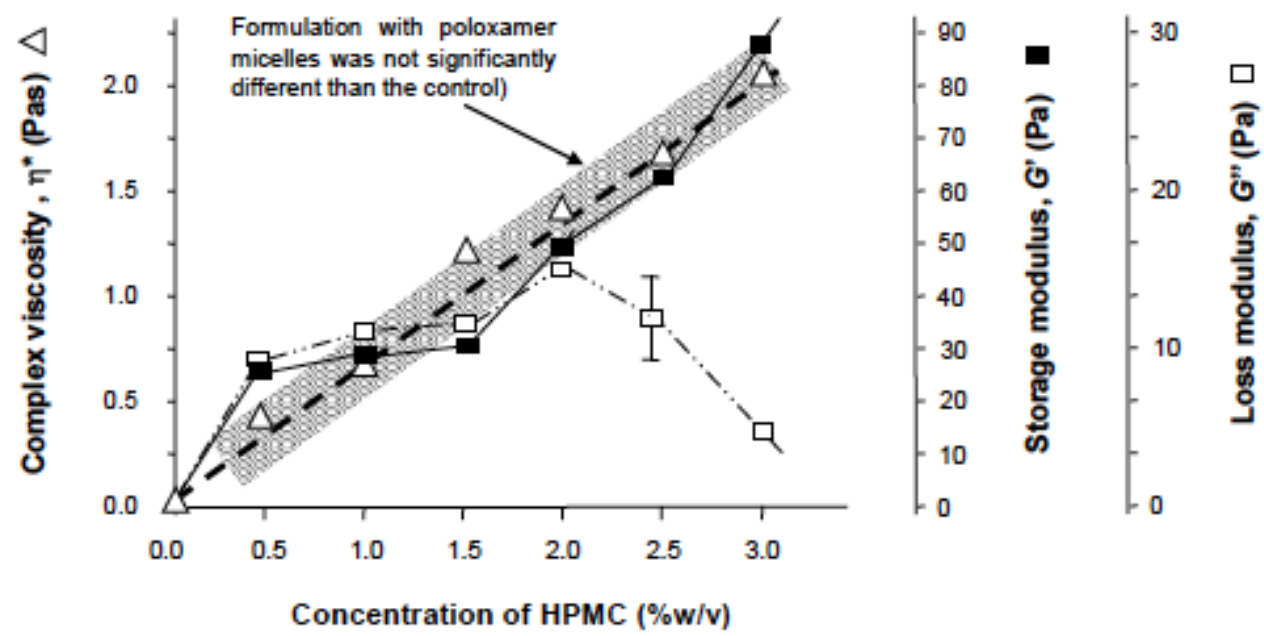

Fig. (7). Complex viscosity $\left(\eta^{*}\right)$ and visco-elasticity as storage and loss moduli, respectively $\left(G^{\prime}, G^{\prime \prime}\right)$ demonstrating the profiles of macroscopic gels for the suspension of copper nanoparticle-carrying polymer nanogels. The hydrogels were carrying a dose of $5 \% \mathrm{w} / \mathrm{v}$ polymer micelles and these micelles encapsulated $15 \% \mathrm{w} / \mathrm{v}$ CuO NPs.

change is minimal. Certainly the zeta-potential for bare $\mathrm{CuO}$ at $\sim 1.5 \mathrm{mV}$ is considerably lower than the $\zeta$-potential expected for colloidal copper, e.g. $\sim 20 \mathrm{mV}$ [3], which might have a bearing for better entrapment and encapsulation.

\subsection{Nanogels and Supramolecular Gels}

Fig. (7) shows the viscosity and visco-elasticity profiles of macroscopic gels for the presence and absence of a suspension of copper nanoparticlecarrying polymer micelles ex vivo. Such multicomponent formulations, are used to aid local retention (for example as a depot in a tumor) in the body for the purposes of antimicrobial therapy, cytotoxin-use chemotherapy and radiotherapy, using radiopharmaceuticals, where the complexity of the "matrix" is an important part of the design of a useful and optimized formulation. This type of vehicle is an ideal means of locus in quo administration of chemotherapeutics and other drugs in vivo [64]. The entrapment of Pluronic 108-coated CuBz NPs in hydrogels is presented in Fig. (7). The rheological behavior of pseudoplastic hydrogels was not significantly altered or structurally different in the presence and absence of poloxamer stabilized CuBzNPs. Altering the concentration of hydrogel gelling agent did however, modify the viscosity, elasticity and visco-elasticity of the NP carrier [35, 39]. HPMC samples demonstrated a viscoelastic behavior as they had both storage, $G^{\prime}$ and loss, $G^{\prime \prime}$ values. However, they also behaved elastic-solid like behavior, as the $G^{\prime}$ storage module was larger than the $G^{\prime \prime}$ loss modulus, especially at concentration $3 \% \mathrm{w} / \mathrm{v}$ where the $G^{\prime}$ peaked at 86 $\mathrm{Pa}$. The HPMC was added into the clear solution to produce concentrations of $0.5 \% \mathrm{w} / \mathrm{v}, 1.0 \% \mathrm{w} / \mathrm{v}$, $1.5 \% \mathrm{w} / \mathrm{v}, 2.0 \% \mathrm{w} / \mathrm{v}, 2.5 \% \mathrm{w} / \mathrm{v}, 3.0 \% \mathrm{w} / \mathrm{v}$ and $3.5 \% \mathrm{w} / \mathrm{v}$. Over the concentration range $0-3 \% \mathrm{w} / \mathrm{v}$ HPMC polymer the complex viscosity increase linearly from 0 to 2.5 Pas. One can gain an idea of the samples with a viscosity of $\sim 2.5$ Pas, as this is the value found in products such as the more viscous version of sweetened condensed milk or nail and wood varnish.

The storage $\left(G^{\prime}\right)$ and loss $\left(G^{\prime \prime}\right)$ moduli profiles with increasing concentration point to rather more complex associate behavior. The loss modulus increases with concentration, then falls off at $>2 \%$ $\mathrm{w} / \mathrm{v}$ from a maximum value of $16 \mathrm{~Pa}$, whereas the storage modulus, also regarded as a description of "elasticity", increases in a non-linear fashion above $2 \% \mathrm{w} / \mathrm{v}$. This can be modelled again an initial production of aggregated materials increasing loss modulus $\left(G^{\prime \prime}\right)$, which at $2 \%$ is translated into intermolecular extension and interaction. Increasing elasticity $\left(G^{\prime}\right)$ is indicative of a continuous network and the formation of extensive intermolecular interactions. Notably, neither the viscosity nor elasticity, in terms of enhancement or interruption, were affected by the poloxamer in the HPMC network of aggregates or chains as evidenced in Fig. (7). Higher $G^{\prime}$ gels of this type with some degree of fluidity will find application for use as image enhancement, MRI or CT contrast agent applications [2, 20], photodynamic therapy agents $[1,3,12,38]$, chemotherapeutic agents 

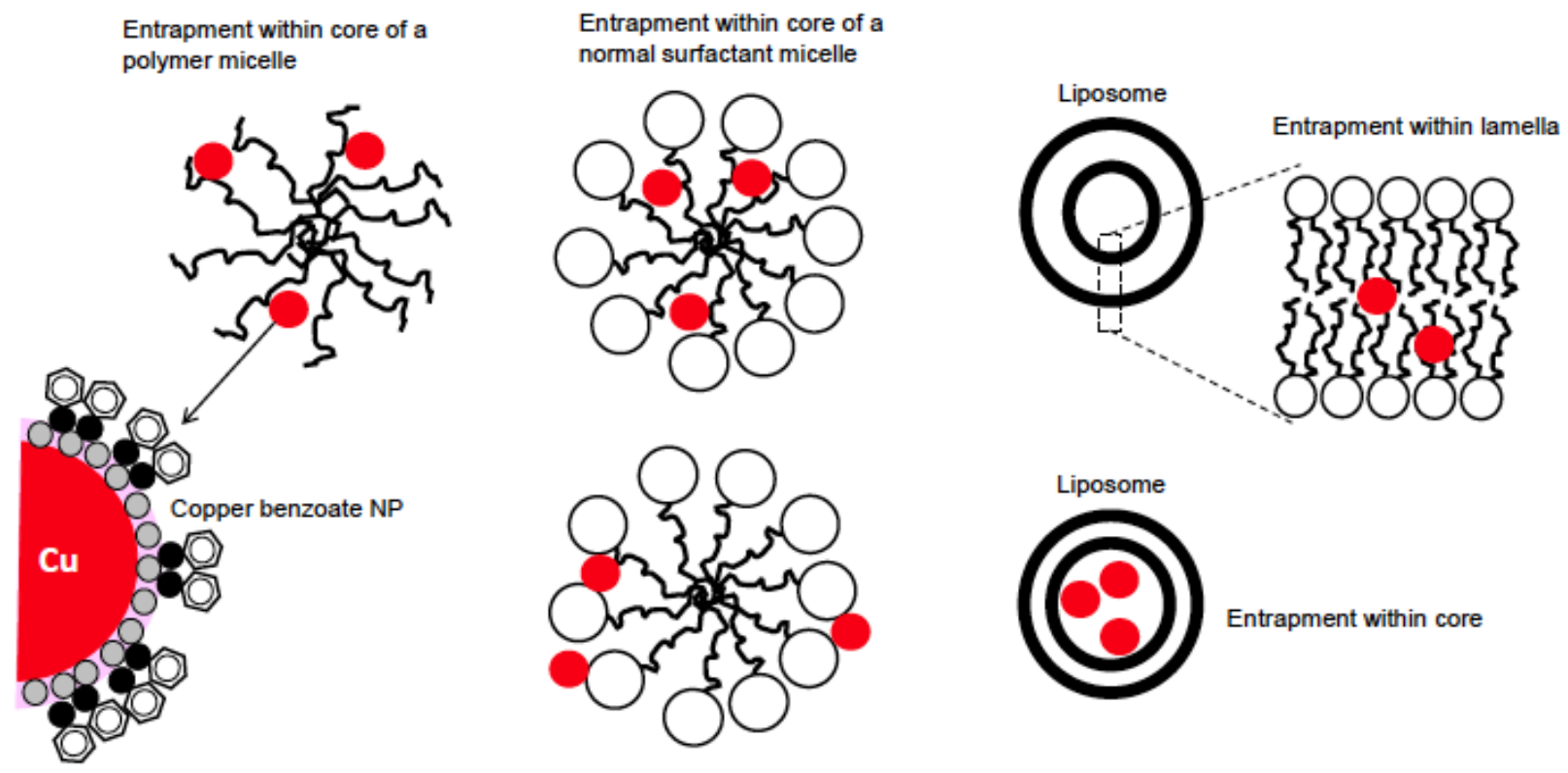

Entrapment within headgroups of a normal surfactant micelle

Part B

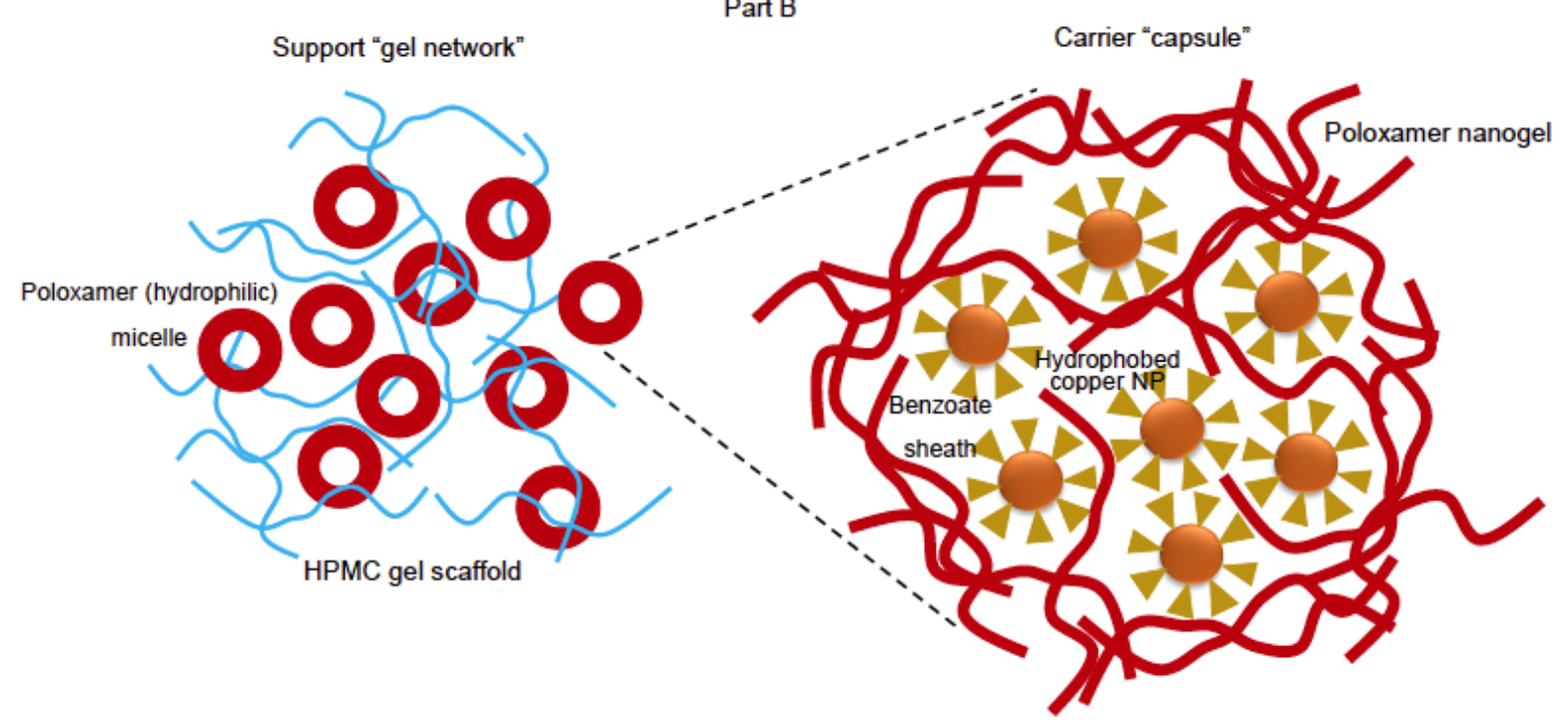

Fig. (8). Cartoon representation of copper nanoparticles (CuNPs) in either colloidal carrier alone or colloidal carrier enveloped by the polymeric materials of a hydrophilic polymer-based supramolecular vehicle and hydrogel. Part A: Phenomenological representation of the entrapments of hydrophobized copper (NPs) within carrier particles which might be micelles and liposomes. Part B: Phenomenological representation of polymer supramolecular structures highlighting the means of encapsulation of metal carrying NPs in an extensive network and gel matrix.

$[9,17,24]$, such as anti-microbial $[11,22]$ or radiotherapy agent applications, with the added advantage of an increased resistance time. Various forms of copper NP can be incorporated into a pseudoplastic (weak gel) supramolecular assembly as illustrated by Fig. (7), without carrier modification and misrepresentation in situ [32, 33], which shows promise as a candidate for injection into the appropriate tissues in the body. Pseudoplastic gels of the type that were formulated can be injected as a concentrated mass in tissues and intradermally as they flow through a syringe needle but have complex viscosities of 0-2.5 Pas. Two applications of metals NPs gaining popularity amongst clinicians is for their use in either brachytherapy for seeding beta or gamma particle emitters $\left({ }^{198} \mathrm{Au},{ }^{55} \mathrm{Fe} /{ }^{59} \mathrm{Fe}\right.$, 
${ }^{99 m} \mathrm{Tc}$ ) or as positron emission therapy (PET) regents that include copper and gallium $\left({ }^{64} \mathrm{Cu}\right.$, ${ }^{66} \mathrm{Ga} /{ }^{68} \mathrm{Ga}$ ). Further studies are needed to indicate the ability of the hydrophobized metal NP or aggregates of particles in tissues to remain in the vicinity of administration to reduce toxic effects.

A phenomenological model illustrating encapsulation and entrapment of the encapsulated moiety in two parts is presented in Fig. (8). Part A shows according to Figs. (1-6) how hydrophobized copper can be incorporated in a soft matter-coated assembly made from surface-active non-ionic biocompatible polymers. Part A also shows the copper-based nanoparticles covered with non-toxic benzoate anions, and having their charge oriented to the metal NP surface can be rendered as lipophilic. This type of hydrophobized NP will then lie in the polymer micelle interior, containing a larger share of apolar residues internalized within its core. By engineering of surface hydrophobicity the crafted NP can be made to reside in the core or hydrated polar sheath of a normal micelle of low molecular weight surfactant or in the aqueous core or lipid/surfactant bilateral of a vesicle. Part B shows how poloxamer coated metal NPs are entrained in a supramolecular structured hydrogel. The chain and aggregate density along with the junction zone and point contacts between adjacent species in the hydrogel determines the viscoelasticity of the gel as indicated in Fig. (7). The spatial distribution of copper within each micelle is unclear at present but the distribution of micelles in the HPMC hydrogel seems more and uniformly dispersed, which is explained by the lack of significant difference in hydrogels in the absence and presence of F108 micelles (Fig. 7).

\section{CONCLUSIONS}

In this study, a simple way of grinding solid to make CuBzNPs from a synthesized copper benzoate powder was used along with uniformly-sized purchased copper oxide nanospheres. The grinding method of $\mathrm{CuBz}$ nanoparticle preparation could be improved to give a higher yield and especially microfiltration could be used to separate NPs with a narrow size distribution. The work confirmed $\mathrm{CuBz}$ as a good candidate for encapsulation during which the study also estimated its lipophilicity by measuring the contact angle of a drop of water placed on $\mathrm{CuBz}$ powder. Although in-house manufactured $\mathrm{CuBzNP}$ size was very polydispersed the approach did illustrate the ability to grade nanoparticle by successive filtration. Dispersal for longer times (hours and days) was undertaken with SDS surfactant or Pluronic F108 rather than bare nanoparticles, which tended to flocculate and sediment rapidly. The copper content of colloidal NPs was successfully confirmed by measuring the content of the sample solutions by MP-AES at a copper specific wavelength. An observable particle size increase, thought to be due to poloxamer molecules covering $\mathrm{CuBz}$ particles was measured by DLS, which indicated higher F108 concentrations caused an incremental increase in measured particle size, possibly due to increased layer-onlayer construction and/or partial flocculation. In future studies it is suggested that making use of SAXS or SANS of CuBzNPs and extension to electron microscopy (TEM or SEM) may provide a clearer understanding of the spatial characteristics of this interaction and confirm the role MNs may play in modifying micelle formation and maintenance. Importantly for the clinical context, non-ionic surfactants such as poloxamer F108 can be used to encapsulate surface-modified toxic metals such as copper for medical use.

\section{CURRENT AND FUTURE DEVELOPMENTS}

This work builds successfully on the background non-medical work associated with paramagnetic materials, semi-conductors and surface plasmon resonance of metallic nanoparticles. Copper oxide and base copper offer great opportunities for use in therapy and diagnostics. Issues of biocompatibility relevant to medicine, can be overcome by hydrophobizing the entities and then incorporating the material in a nano-carrier. This work then continues and uses transferable chemical approaches used for simple organic molecules for the purposes of metallic nanoparticle incorporation in dosing-relevant hydrogels. The next step would be to use such samples for in vivo testing using animal models.

\section{ETHICS APPROVAL AND CONSENT TO PARTICIPATE}

Not applicable.

\section{HUMAN AND ANIMAL RIGHTS}

No Animals/Humans were used for studies that are the basis of this research. 


\section{CONSENT FOR PUBLICATION}

Not applicable.

\section{CONFLICT OF INTEREST}

The authors declare no conflict of interest, financial or otherwise.

\section{ACKNOWLEDGEMENTS}

Yunlong Xu would like to thank the funds from Hundred Sail Away Project in 2015 by Jiangxi Provincial Party Committee Organization Department and Jiangxi Association for Science and Technology. The authors are sincerely grateful for the financial support from the Jiujiang Vocational and Technical College to permit a sabbatical to the University of Brighton (Ref: jxkxgjb201592). Kaspars Melkis, Chinn Tyng Sia and Yunlong Xu were responsible for performing experimental work and initial drafting of the results and discussion of findings for the report written by Dipak Sarker with additional experimentation.

\section{REFERENCES}

[1] Juzenas P, Chen W, Sun Y-P, et al. Quantum dots and nanoparticles for photodynamic and radiation therapies of cancer. Adv Drug Deliv Rev 2008; 60(15): 1600-14.

[2] Janib SM, Moses AS, MacKay JA. Imaging and drug delivery using theranostic nanoparticles. Adv Drug Deliv Rev 2010; 62(11): 1052-63.

[3] El-Trass A, ElShamy H, El-Mehasseb I, et al. CuO nanoparticles: Synthesis, characterization, optical properties and interaction with amino acids. Appl Surf Sci 2012; 258: 2997-3001.

[4] Gopal A, Kant V, Gopalakrishnan A, et al. Chitosanbased copper nanocomposite accelerates healing in excision wound model in rats. Eur J Pharmacol 2014; 731: 8-19.

[5] Rezaeifard A, Jafarpour M, Naeimi A, et al. Highly selective aqueous heterogeneous oxygenation of hydrocarbons catalyzed by recyclable hydrophobic copper (II) phthalocyanine nanoparticles. J Mol Catalysis A: Chem 2012; 357: 141-7.

[6] Bahadar H, Maqbool F, Niaz K, et al. Toxicity of Nanoparticles and an Overview of Current Experimental Models. Iranian Biomed J 2016; 20(1): 1-11.

[7] Bondarenko O, Juganson K, Ivask A, et al. Toxicity of $\mathrm{Ag}, \mathrm{CuO}$ and $\mathrm{ZnO}$ nanoparticles to selected environmentally relevant test organisms and mammalian cells in vitro: a critical review. Arch Toxicol, 2013; 87: $1181-1200$.

[8] Elsaesser A, Howard CV. Toxicology of nanoparticles. Adv Drug Deliv Rev 2012; 64(2):129-37.

[9] Tsapis N, Bennett D, Jackson B, et al. Trojan particles: Large porous carriers of nanoparticles for drug delivery. Proc Nat Acad Sci (USA) 2002 ; 99(19): 12001-5.

[10] David Gara PM, Garabano N, Llansola Portoles MJ, et al. ROS enhancement by silicon nanoparticles in $\mathrm{X}$-ray irradiated aqueous suspensions and in glioma C6 cells. J Nanopartic Res 2012; 14(3): 1-13.

[11] Li W-R, Xie X-B, Shi Q-S, et al. Antibacterial activity and mechanism of silver nanoparticles on Escherichia coli. Appl Microbiol Biotech 2010; 85(4): 111522.

[12] Dichello GA, Sarker DK. In: Grumezescu A, Ficai A, Eds. Nanostructures in Therapeutic Medicine, Volume 2: Nanostructures for Antimicrobial Therapy. Netherlands: Elsevier 2016; pp. 272-313.

[13] Jain PK, Huang X, El-Sayed IH, et al. Noble Metals on the Nanoscale: Optical and Photothermal Properties and Some Applications in Imaging, Sensing, Biology, and Medicine. Acc Chem Res 2008; 41(12): 1578-86.

[14] Takahashi M, Mohan P, Nakade A, et al. $\mathrm{Ag} / \mathrm{FeCo} / \mathrm{Ag}$ Core/Shell/Shell Magnetic Nanoparticles with Plasmonic Imaging Capability. Langmuir 2015; 31(7): 2228-36.

[15] Gaucher G, Dufresne M-H, Sant VP, et al. Block copolymer micelles: preparation, characterization and application in drug delivery. J Control Rel 2005; 109(1-3): 169-88.

[16] Kozlov MY, Melik-Nubarov NS, Batrakova EV, et al. Relationship between Pluronic Block Copolymer Structure, Critical Micellization Concentration and Partitioning Coefficients of Low Molecular Mass Solutes. Macromol 2000; 33(9): 3305-13.

[17] Lo C-L, Lin S-J, Tsai H-C, et al. Mixed micelle systems formed from critical micelle concentration and temperature-sensitive diblock copolymers for doxorubicin delivery. Biomat 2009; 30(23-24):396170.

[18] Mistry K, Sarker DK. SLNs can Serve as the New Brachytherapy Seed: Determining Influence of Surfactants on Particle Size of Solid Lipid Microparticles and Development of Hydrophobised Copper Nanoparticles for Potential Insertion. J Chem Eng Proc Technol 2016; 7(3): 1-9.

[19] Dichello GA, Fukuda T, Maekawa T, et al. Preparation of liposomes containing small gold nanoparticles using electrostatic interactions. Eur J Pharm Sci 2017; 105: 55-63.

[20] Kim TJ, Chae KS, Chang Y, et al. Gadolinium oxide nanoparticles as potential multi-modal imaging and therapeutic agents. Curr Top Med Chem 2013; 13(4): 422-33.

[21] Mody VV, Siwale R, Singh A, et al. Introduction to metallic nanoparticles. J Pharm Bioallied Sci 2013; 2(4): 282-9.

[22] Baek Y-W, An Y-J. Microbial toxicity of metal oxide nanoparticles $\left(\mathrm{CuO}, \mathrm{NiO}, \mathrm{ZnO}\right.$ and $\left.\mathrm{Sb}_{2} \mathrm{O}_{3}\right)$ to Escherichia coli, Bacillus subtilis and Staphylococcus aureus. Sci Total Env 2011; 409 (8): 1063-68.

[23] Zhang Q, Zhang K, Xu D, et al. CuO Nanostructures: Synthesis, characterization, growth mechanisms, fundamental properties and applications. Prog Mat Sci 2014; 60: 208-337. 
[24] Avgoustakis K, Beletsi A, Panagi Z, et al. PLGAmPEG nanoparticles of cisplatin: in vitro nanoparticle degradation and in vivo residence in blood properties. J Control Rel 2002; 79: 123-35.

[25] Gamucci O, Bertero A, Gagliardi M, et al. Biomedical Nanoparticles: Overview of Their Surface Immune-Compatibility. Coatings 2014; 4(1): 139-59.

[26] Sabella S, Carney RP, Brunetti V, et al. A general mechanism for intracellular toxicity of metalcontaining nanoparticles. Nanoscale 2014; 6(12): 7052-61.

[27] Chang H, Chen X-Q, Jwo C-S, et al. Electrostatic and Sterical Stabilization of $\mathrm{CuO}$ Nanofluid Prepared by Vacuum Arc Spray Nanofluid Synthesis System (ASNSS). Mat Trans 2009; 50(8): 2098-103.

[28] Aruoja V, Dubourgier H-C, Kasemets K, et al. Toxicity of nanoparticles of $\mathrm{CuO}, \mathrm{ZnO}$ and $\mathrm{TiO}_{2}$ to microalgae Pseudokirchneriella subcapitata. Sci Total Env 2009; 407 (4): 1461-8.

[29] Onoshima D, Yukawa H, Baba Y. Multifunctional quantum dots-based cancer diagnostics and stem cell therapeutics for regenerative medicine. Adv Drug Del Rev 2015; 95(1): 2-14.

[30] Kharlamov AN, Tyurnina AE, Veselova VS, et al. Silica-gold nanoparticles for atheroprotective management of plaques: results of the NANOM-FIM trial. Nanoscale 2015; 7(17): 8003-15.

[31] Lajunen T, Viitala L, Kontturi L-S, et al. Light induced cytosolic drug delivery from liposomes with gold nanoparticles. J Control Rel 2015; 203: 85-98.

[32] Thanh NTK, Green LAW. Functionalisation of nanoparticles for biomedical applications. Nano Today 2010; 5(3): 213-30.

[33] Locatelli E, Broggi F, Ponti J, et al. Lipophilic Silver Nanoparticles and Their Polymeric Entrapment into Targeted-PEG-Based Micelles for the Treatment of Glioblastoma. Adv Healthcare Mat 2012; 1(3): 342-7.

[34] Sarker DK. In: Tiwari A, Ramalingam M, Kobayashi h, Turner APF, Eds. Biomedical Materials and Diagnostic Devices, Chapter 13, Part III. New York: Scrivener Publishing; pp395-434.

[35] Sarker DK. Architectures and mechanical properties of drugs and complexes of surface-active compounds at air-water and oil-water interfaces. Curr Drug Discov Technol 2018; 14: 1-24. DOI: $10.2174 / 1570163814666171117132202$.

[36] Ponnappan N, Chugh A. Nanoparticle-Mediated Delivery of Therapeutic Drugs. Pharm Med 2015; 29(3): 155-67.

[37] Howell M, Mallela J, Wang C, et al. Manganeseloaded lipid-micellar theranostics for simultaneous drug and gene delivery to lungs. J Control Rel 2013; 167(2): 210-18.

[38] Probst CE, Zrazhevskiy P, Bagalkot V, et al. Quantum dots as a platform for nanoparticle drug delivery vehicle design. Adv Drug Del Rev 2013; 65(5), 70318.

[39] Collins G, Patel A, Dilley A, et al. Molecular modeling directed by an interfacial test apparatus for the evaluation of protein and polymer ingredient function in situ. J Agric Food Chem 2008; 56(10): 3846-55.
[40] Al-Hanbali O, Rutt KJ, Sarker DK, et al. Concentration dependent structural ordering of Poloxamine 908 on polystyrene nanoparticles and their modulatory role on complement consumption. J Nanosci Nanotech 2006; 6 (9): 3126-33.

[41] Georgiev GA, Sarker DK, Al-Hanbali O, et al. Effects of poly(ethylene glycol) chains conformational transition on the properties of DMPC/DMPE-PEG thin liquid films and monolayers. Coll Surf B: Biointerfac 2007; 59(2): 184-93.

[42] Kothur RR, Fucassi F, Dichello G, et al. Synthesis and applications of co-pillar[5]arene dithiols. Supramol Chem 2015; 28(5-6): 436-443

[42] Umlong IM, Ismail K. Micellization behavior of sodium dodecyl sulfate in different electrolyte media. Coll Surf A: Physicochem Eng Aspects 2007; 299(1): 8-14.

[43] Corrin ML, Harkins WD. The Effect of Salts on the Critical Concentration for the Formation of Micelles in Colloidal Electrolytes. J Am Chem Soc 1947; 69(3): 683-688.

[44] Alexandridis P, Hatton TA. Poly(ethylene oxide)poly(propylene oxide)-poly (ethylene oxide) block copolymer surfactants in aqueous solutions and at interfaces: thermodynamics, structure, dynamics, and modeling. Coll Surf A: Physicochem Eng Aspects 1995; 96: 1-46.

[45] Alexandridis P, Holzwarth JF, Hatton TA. (1994) Micellization of Poly(ethylene oxide)-Poly(propylene oxide)-Poly(ethylene oxide) Triblock Copolymers in Aqueous Solutions: Thermodynamics of Copolymer Association. Macromol 1994; 27(9): 2414-25.

[46] Sharma PK, Reilly MJ, Jones DN, et al. The effect of pharmaceuticals on the nanoscale structure of PEOPPO-PEO micelles. Coll Surf B: Biointerfac 2008; 61(1): 53-60.

[47] Mout R, Moyano DF, Rana S, et al. Surface functionalization of nanoparticles for nanomedicine. Chem Soc Rev 2012; 41(7): 2539-44.

[48] Beatty SM, Smith JE. Fractional wettability and contact angle dynamics in burned water repellent soils. J Hydrology 2010; 391(1-2): 97-108.

[49] Marmur A. Soft contact: measurement and interpretation of contact angles. Soft Matter 2006; 2(1): 12-17.

[50] Bayer IS, Fragouli D, Martorana PJ, et al. Solvent resistant superhydrophobic films from selfemulsifying carnauba wax-alcohol emulsions. Soft Matter 2011; 7: 7939.

[51] Mańko D, Zdziennicka A, Jańczuk B. Surface tension of polytetrafluoroethylene and its wetting by aqueous solutions of some surfactants and their mixtures. Appl Surf Sci 2017; 392: 117-25.

[52] Andrieu C, Sykes C, Brochard F. Average Spreading Parameter on Heterogeneous Surfaces. Langmuir 1994; 10(7): 2077-80.

[53] Decker EL, Frank B, Suo Y, et al. Physics of contact angle measurement. Coll Surf A: Physicochem Eng Aspects 1999; 156(1-3):177-89.

[54] Deguchi S, Mukai S-A, Tsudome M, et al. Facile generation of fullerene nanoparticles by handgrinding. Adv Mat 2006; 18(6):729-32. 
[55] Striemer CC, Fauchet PM, McGrath JL, et al. Chargeand size-based separation of macromolecules using ultrathin silicon membranes. Nature 2007; 445(7129):749-53.

[56] Dutta A, Dolui SK. Preparation of colloidal dispersion of $\mathrm{CuS}$ nanoparticles stabilized by SDS. Mat Chem Phys 2008; 112(2):448-52.

[57] Almgren M, Gimel JC, Wang K, et al. SDS Micelles at High Ionic Strength. A Light Scattering, Neutron Scattering, Fluorescence Quenching, and CryoTEM Investigation. J Coll Interface Sci 1998; 202(2): 222231.

[58] Allen C, Maysinger D, Eisenberg A. Nanoengineering block copolymer aggregates for drug delivery. Coll Surf B: Biointerfac 1999; 16(1-4): 3-27.

[59] Alexandridis P, Nivaggioli T, Hatton TA. Temperature effects on structural properties of Pluronic P104 and F108 PEO-PPO-PEO block copolymer solutions. Langmuir 1995; 11(5): 1468-76.
[60] Santander-Ortega MJ, Jódar-Reyes AB, Csaba N, et al. Colloidal stability of Pluronic F68-coated PLGA nanoparticles: A variety of stabilization mechanisms. J Coll Interface Sci 2006; 302(2):522-9.

[61] Trokhymchuk A, Henderson D. Depletion forces in bulk and in confined domains: From AsakuraOosawa to recent statistical physics advances. Curr Opin Coll Interface Sci 2015; 20(1): 32-8.

[62] Tiraferri A, Chen KL, Sethi R and Elimelech M. Reduced aggregation and sedimentation of zero-valent iron nanoparticles in the presence of guar gum. J Coll Interface Sci 2008; 324(1-2): 71-9.

[63] Govender S, Jacobs EP, Bredenkamp, MW, Swart P. A robust approach to studying the adsorption of Pluronic F108 on nonporous membranes. J Coll Interface Sci 2005; 282(2): 306313.

[64] Kataoka K, Harada A, Nagasaki Y. Block copolymer micelles for drug delivery: design, characterization and biological significance. Adv Drug Del Rev 2001; 47(1): 113-31. 